21.2

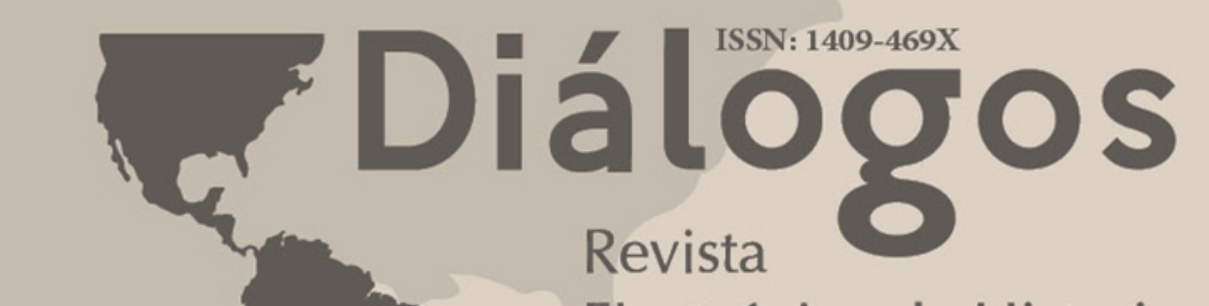

Electrónica de Historia

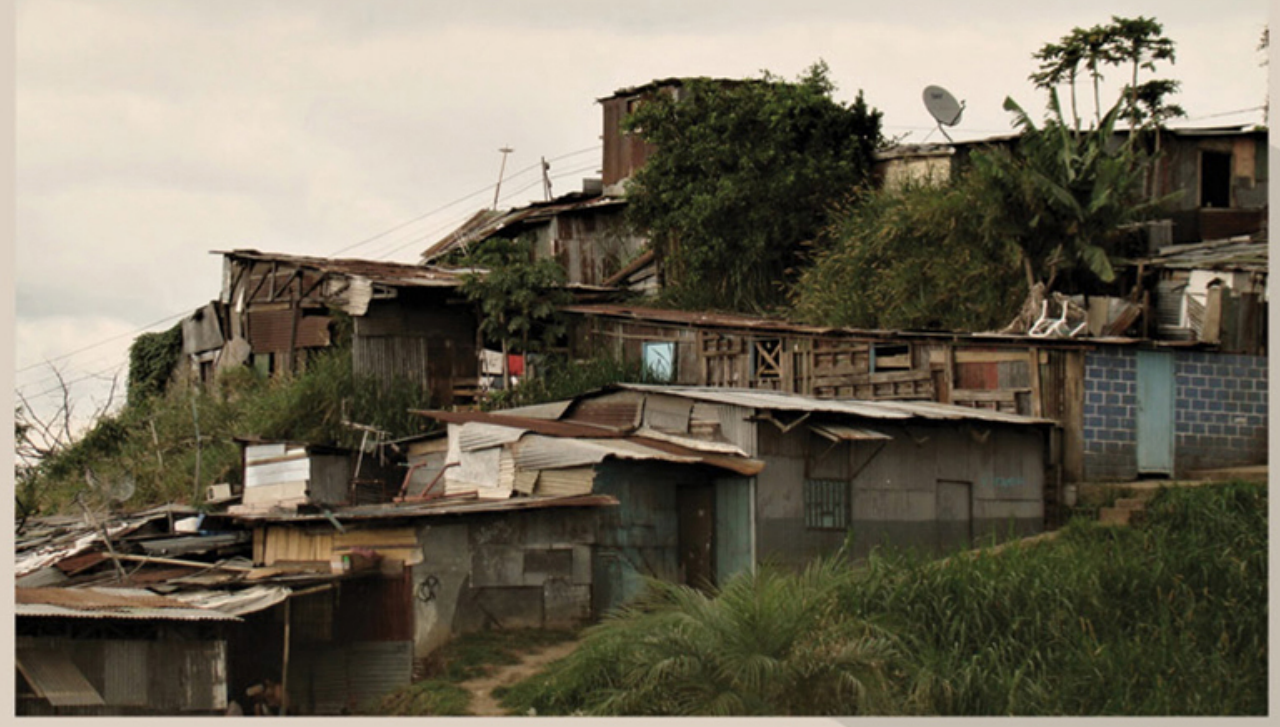

Centro de Investigaciones Históricas de América Central. Universidad de Costa Rica Julio-diciembre 2020

url: http://revistas.ucr.ac.cr/index.php/dialogos/index
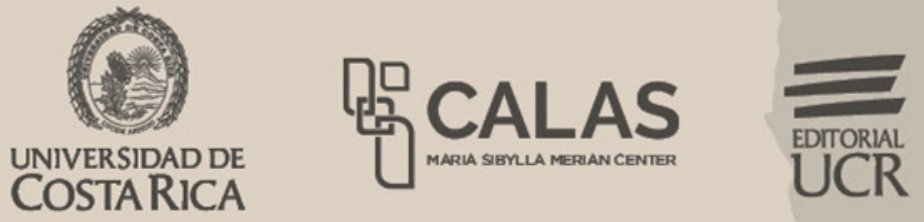


\title{
LA INCORPORACIÓN DE LA HACIENDA "EL MURCIÉLAGO" EN EL TERRITORIO DEL PARQUE NACIONAL SANTA ROSA: UN PROYECTO GEOPOLÍTICO (1978-1986)
}

\author{
Gabriel Madriz-Sojo \\ Ronald Díaz Bolaños
}

\begin{abstract}
Resumen
El presente trabajo visibiliza el territorio del Sector Murciélago del Parque Nacional Santa Rosa. No solamente como una zona protegida con remanentes de bosque tropical seco y especialmente relevante por su resguardo de los ecosistemas del Pacífico Seco costarricense, sino también como un espacio de poder que, condicionado por su situación limítrofe con Nicaragua y el contexto geopolítico centroamericano e internacional, esta zona vio reconfiguradas sus prácticas humanas desarrolladas durante el período de estudio. Lo anterior debido a cambiantes disposiciones de las élites políticas nacionales: desde una inicial tendencia conservacionista con la expropiación hacendaria durante la administración Carazo Odio (1978-1982) a una intensificación militar y transgresión ambiental durante la administración Monge Álvarez (1982-1986) y continuada, pero gradualmente dirimida, durante el primer año de la administración Arias Sánchez (19861990). A través de un análisis documental de fuentes de archivo, hemerográficas, secundarias y mapas, el artículo desarrolla un recorrido histórico de los principales procesos de aprovechamiento, uso y redistribución territorial del espacio señalado, contribuyendo a la desmitificación de discursos oficiales respeto a los proyectos de conservación del Estado costarricense. Finalmente, esta concluye que la estricta aplicación de las políticas de conservación dentro de la zona estudiada se vio constreñida por una variable agenda política de seguridad nacional, una canalización de demandas de grupos sociales, inconstantes flujos presupuestarios debido a la crisis económica de inicios de la década de 1980 y una denotada desidia institucional en la gestión del parque.
\end{abstract}

Palabras clave: conservación ambiental, historia contemporánea, geopolítica, parque nacional, política y gobierno. 


\title{
HACIENDA “EL MURCIÉLAGO” INCORPORATION TO SANTA ROSA NATIONAL PARK: A GEOPOLITICAL SCHEME (1978-1986)
}

\begin{abstract}
This paper approaches the emergence of Murciélago's area from Santa Rosa National Park not only as a protected area with remnants of the dry tropical forest (especially relevant due to its conservation of Costa Rica's north pacific regional ecosystems), but also as a power space, conditioned by its border location with Nicaragua and Central American and international geopolitical contexts. This zone experienced several reconfigurations of social practices developed during the temporal scale of study. This reconfigurations were due to the changing elite policies: from an incipient conservationist tendency initiated by Hacienda "El Murciélago" expropriation during president Carazo Odio's administration (19781982), to a military intensification and environmental transgression during Monge Álvarez's administration (1982-1986), and continued but gradually diminished at the first year of Arias Sánchez's administration (1986-1990). Through an analysis of archival, hemerographic, secondary sources, and maps, the paper develops a historical journey through the main processes of land use, territory exploitation, and distribution occurred in the mentioned space, contributing to the demystification of official speeches regarding conservation projects held by the Costa Rican State. Finally, the paper concludes that the strict implementation of binding conservationist policies inside Murcielago's sector have been limited by a variety of political agendas in national security, a channeling of demands from various social sectors due to the economic crisis of the early 1980's, and a marked institutional negligence in the park management.
\end{abstract}

Keywords: environmental conservation, contemporary history, geopolitics, national parks, politics and government. 


\section{INTRODUCCIÓN}

Las prácticas conservacionistas en Costa Rica se han caracterizado por una cobertura de protección de un vasto porcentaje del territorio nacional ${ }^{1}$. Esto como producto de las políticas ambientales y estrictas regulaciones emergentes del aparato estatal sobre espacios protegidos. Estas prácticas han permitido contener las dinámicas de colonización, explotación y producción propias de las sociedades capitalistas de los siglos XX y XXI, siendo así los parques nacionales costarricenses baluartes en la atención de los ecosistemas en estado natural y en la preservación de su diversidad ecológica y genética (Morera \& Romero, 2013, p. 31). Esto como un objetivo complementario al mantenimiento estético del paisaje o de la belleza escénica de sus zonas verdes boscosas. De esta forma, el Estado como protagonista de dicha reconfiguración, transformación y gestión territorial en distintos contextos históricos ha sido el principal actor responsable del desenvolvimiento particular de prácticas sociales y humanas en relación con el ambiente natural, así como de la organización y control efectivo de dichos espacios. Un ejemplo de ello ha sido la administración del Sector Murciélago (SM) del Parque Nacional Santa Rosa (PNSR) durante el período 1978-1986 en plena época de Guerra Fría.

Este sector guarda una especial relevancia geográfica debido a que, adscrito a las 38 mil hectáreas de extensión terrestre y a las 43 mil hectáreas marinas totales del parque:

[conserva] un ecosistema completo de bosque tropical $\operatorname{seco}^{2} \ldots$ [el] más representativo en Centroamérica, incluye[ndo] especies forestales como: guanacaste, pochote, guapinol, indio desnudo y caoba. Especies [de] mamíferos como: venado cola blanca, mono congo, mono cara blanca, pizotes, así como numerosas especies de aves y anfibios. (Quirós, 2017, p. 100)

Lo cual significa un aporte no sólo a la biodiversidad regional, sino también a la variabilidad panorámica natural del territorio costarricense con sus paisajes de sabana y pastos, de secuencias rocosas, así como paisajes boscosos ${ }^{3}$ de distintas alturas y variantes vegetales. Por ejemplo, se puede apreciar desde arbustos y pequeñas especies deciduas, hasta árboles maduros siempreverdes con hoja perenne de gran tamaño (Denyer, 2013; Vargas, 2016) (véase Figura 1). Tampoco se puede desdeñar la trascendencia geológica del lugar puesto que, dentro del SM, en la Península de Santa Elena, se localizan "rocas ultrabásicas del Cretácico, como la peridotita serpentinizada, que se considera material intrusivo proveniente del manto [terrestre] y forma parte de las rocas más antiguas del país” (Boza, 1984, p. 15). 


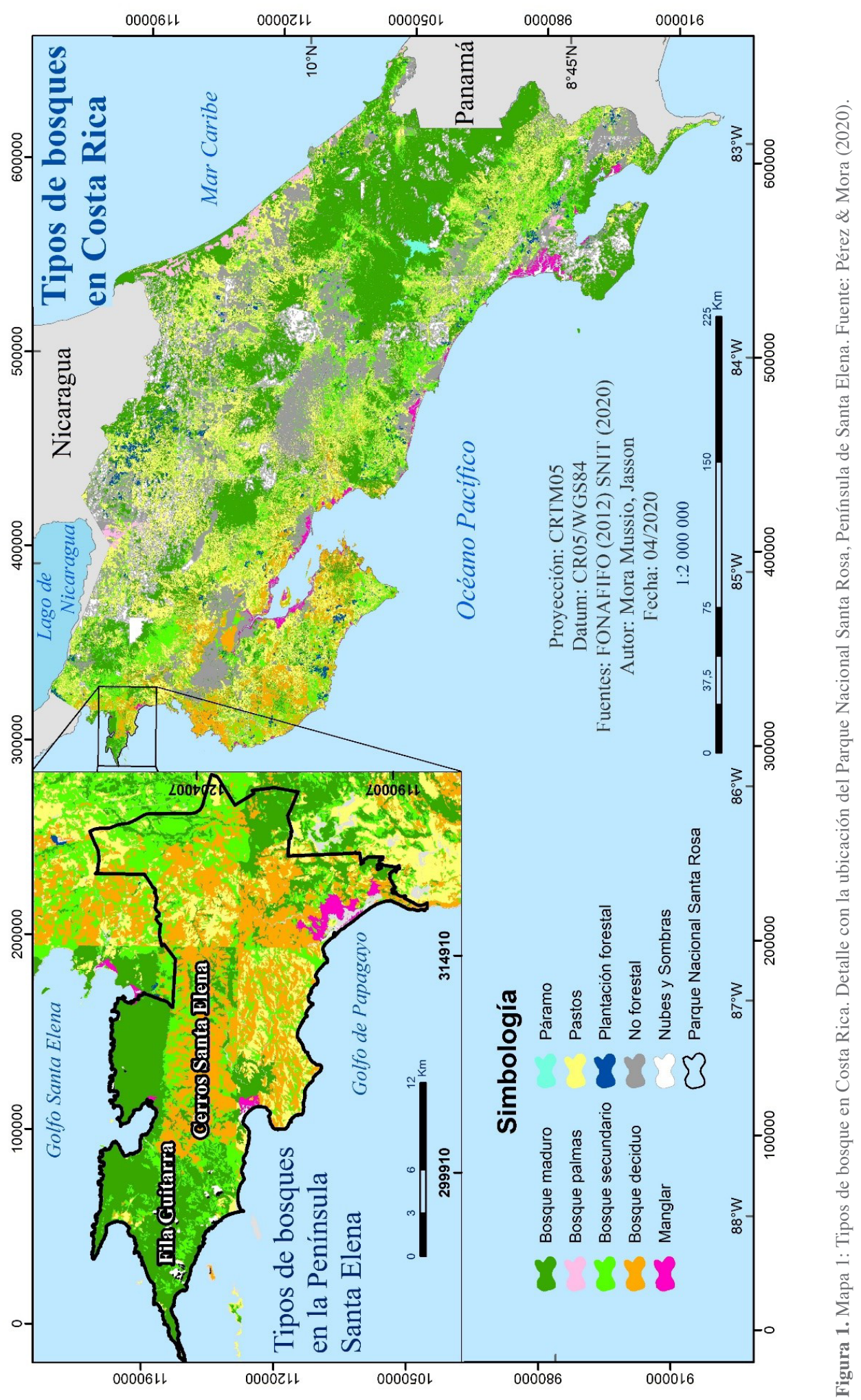


Igualmente, desde la segunda mitad del siglo XX han sido de interés por parte de diferentes agentes sociales locales y extranjeros tanto el manglar, las playas (costas), los cerros y el mismo bosque del SM (Díaz, Mora \& Madriz, 2019; Evans, 1999; Rowe, 2011). Lo último para la subsistencia de pequeños pobladores a través de la cacería, la agricultura y la extracción de leña (Área de Conservación Guanacaste, 2012b). A mayor escala el comercio de hato ganadero bovino, la explotación salinera y forestal fueron labores industriosas emprendidas allí por un número limitado de patronos latifundistas (Díaz, Mora \& Madriz, 2019; Edelman, 1994). También ha sido lugar para actividades educativas, turísticas y de investigación científica (Quirós, 2017). Asimismo, sirvió de base para operaciones de seguridad y de tipo militar desarrolladas por costarricenses, nicaragüenses y hasta estadounidenses (Evans, 1999).

En esta área, durante las décadas de 1960 y 1970, operaba la hacienda "El Murciélago" ", propiedad de aproximadamente 16.075 hectáreas pertenecientes al dictador nicaragüense Anastasio Somoza Debayle (1925-1980) ${ }^{5}$. Esta estructuró sus actividades económicas en torno a la ganadería extensiva y fue emprendida por migrantes nicaragüenses y costarricenses. Debido a su ubicación geográfica, cercana a la línea fronteriza con el vecino país y con salida al mar, a través de ella fue posible el contrabando de reses y madera hacia Nicaragua. De igual manera, se hicieron factibles las estadías vacacionales de Somoza en su casa de playa volcada frente al Golfo de Santa Elena. También fue característico del período la especulación de tierras y las incursiones de la Guardia Nacional de Nicaragua en la defensa de los límites hacendarios, la intimidación de precaristas o vecinos errantes dedicados al abigeato y, sobre todo, el control fronterizo ante insurgencias antisomocistas desde Costa Rica ${ }^{6}$ (Edelman, 1998, pp.266-279).

En este sentido, como lo establece Edelman, la hacienda constituía una suerte de "Estado dentro de un Estado" (1994, p. 21) y una afrenta para la soberanía costarricense de acuerdo con la opinión pública del momento ("Aprobada la expropiación", 1979). Es así como en el contexto de crisis social nicaragüense (desde su guerra civil, la Revolución Sandinista contra la dictadura somocista y con una etapa culminante de crispación bélica hacia finales de la década de 1970), esta cuestión significó un planteamiento político en el seno del consejo de gobierno costarricense de la administración de Rodrigo Carazo Odio (1926-2009) para la expropiación de dicha extensa propiedad ${ }^{7}$. Esta se ejecutaría seguidamente y a partir de ello tanto ésta como la consiguiente administración de Luis Alberto Monge Álvarez (19252016) emprenderían dos visiones bifurcadas con respecto a la conservación y el aprovechamiento territorial del espacio nacionalizado.

Evidentemente aquende el ambiente de Guerra Fría (1945-1991) sostenido entre las superpotencias de Estados Unidos (EE. UU) y la Unión Soviética (URSS) y basado en la disputa indirecta del control político en aquellas áreas de influencia e interés geoestratégico, se intensificará en la llamada "tercera oleada de revoluciones del siglo XX" entre 1974 y 1979 (Hobsbawm, 1999, p. 249). 
Esto al gestarse un cambio o transición de régimen en un país muy cercano al Canal de Panamá (lugar de importancia comercial e instalaciones milicianas norteamericanas), implicando no solamente una oportunidad para una inédita incursión socialistasoviética en Centroamérica, sino también para una reacción intervencionista estadounidense que minase la afrenta y proyecto del Frente Sandinista de Liberación Nacional (FSLN). Todo esto ocurre con la desmilitarizada Costa Rica en el medio, teniéndose que adaptar a las circunstancias de la Realpolitik del momento: enhebrando sus limitados recursos diplomáticos y gestionando el territorio limítrofe con Nicaragua (siendo parte de él, el SM) en aras de su defensa territorial soberana, la preservación de la democracia y de la paz regional (Rojas, 1985, p. 84).

La política exterior hacia el "Tercer Mundo" preparada por el presidente norteamericano Jimmy Carter (1924-) a finales de su mandato (1977-1981) fue tardía e infructífera para impedir con previsión el triunfo sandinista y la caída de su régimen satélite para julio de 1979, cuya autoridad política se enfrascaría en un autoexilio a Paraguay (Powaski, 2000, p. 271; Edelman, 1994). En este sentido, tanto los programas de ayudas económicas enviados a destiempo y las cuantiosas concesiones crediticias conseguidas por los EE. UU no impidieron que "un movimiento fundamentalmente socialista" se instaurara en el poder y "firma[ra] un acuerdo comercial con Moscú" en 1980 (Powaski, 2000, pp. 271-272). Mucho menos lo paralizó las precedentes y fallidas presiones a Somoza para que implementase reformas sociales en su país, así como para un ablandamiento de su modo de gobierno hacia el respeto de los derechos humanos (Powaski, 2000, pp. 271-272). El año siguiente, a raíz de la cooperación internacional nicaragüense a la causa guerrillera en El Salvador, es que Carter consideraría suspender toda asistencia financiera hacia su exaliado país y más bien le propinaría una presión bélica directa con el aporte de hasta $\$ 1.000 .000$ en "fuerzas antisandinistas (...), la llamada «contra»" (Powaski, 2000, p. 272).

Con la administración norteamericana entrante (1981-1989) de Ronald Reagan (1911-2004), sobre todo en sus primeros años caracterizados por "la fiebre militar y la retórica apocalíptica" (Hobsbawm, 1999, p. 251), se empleó una profundización del viraje "duro" de la política exterior más reciente de su predecesor. Denominada como "doctrina Reagan" y aunada al plan roll back (tendiente a recuperar el dominio político en Nicaragua) y a una intención de mantener la "subordinación" de los demás países centroamericanos y caribeños, este líder político dispuso como diagnóstico correspondiente a que el principal problema intrarregional centroamericano era expansión de la égida comunista (Powaski, 2000, p. 289; Rojas \& Solís, 1993, p. 12). De ahí que multiplicara a \$ 19.000.000 el financiamiento norteamericano "a una fuerza militar integrada por 500 hombres, la llamada «contra», que se encargaría de sabotear la economía nicaragüense" (Powaski, 2000, p. 289), la cual llegaría incluso a operar desde Costa Rica. Además, como consecuencia de dicha mentalidad anticomunista, solo de forma limitada y subsidiaria EE.UU apoyaría monetariamente al resto de dichas naciones (menos a Granada y El Salvador por sus inclinaciones ideológicas disruptivas) a través de la llamada "Iniciativa de la Cuenca del Caribe" (Powaski, 2000, p. 289). 
Este factor extranjero y su presión sobre la zona limítrofe norte sin duda incide en el comportamiento estatal costarricense y en las gestiones tanto burocráticas como gubernamentales que entablaron las administraciones nacionales citadas y al inicio de la correspondiente a Oscar Arias Sánchez (1940). En consecuencia, los márgenes de maniobra para desarrollar políticas tanto públicas agrarias, de ordenamiento territorial y principalmente de conservación ambiental estuvieron siempre constreñidas por los vaivenes del contexto exterior, focalizando las intervenciones públicas a lo largo de la franja fronteriza y no siendo el SM la excepción para el período de 1978-1986.

Con el objetivo de estudiar estos procesos, se incorpora la perspectiva teórica de la Geohistoria que asume que un producto o espacio geográfico de estudio en particular resulta de la interacción y relación continua entre los grupos humanos y el ambiente natural (González \& Llancavil, 2017, p. 383). Este viene determinado por procesos históricos previos de una datación más longeva, generalmente coyunturas o eventos que históricamente redefinen, deconstruyen e impactan prácticas arraigadas o estructuras socioculturales y políticas (de control) en un territorio dado (González \& Llancavil, 2017, pp. 383-384). Se adhiere el referente teórico de la Geografía Política que consiste en dimensionar todo proceso político (p.ej. el proyecto de Estado-Nación) como determinante en las configuraciones territoriales, pero no solo con énfasis en los recursos naturales vitales que se llegan a controlar por parte del poder estatal, sino también en el poder o mandato desplegado sobre la población (y sus dinámicas particulares) que opera dentro de una región dada (Montoya, 2011, p. 104). Lo anterior sigue los postulados de Friedrich Ratzel (1844-1904), de ahí que se hable de espacio de poder (Stogiannos, 2019, p. 135).

De modo que el presente artículo hace un recorrido histórico sobre la materialización de los proyectos geopolíticos vinculados a "El Murciélago" según su contexto y la naturaleza de las administraciones como principales actores de poder en la reconfiguración de su espacio. Esto a través de un análisis documental de archivos, legislación y mapas recopilados del Archivo Nacional de Costa Rica y del Departamento de Servicios Bibliotecarios, Documentación e Información de la Asamblea Legislativa de la República de Costa Rica, así como de fuentes hemerográficas y otras de tipo secundarias. El estudio tiene una importancia particular en la medida en que presenta una visión alternativa al discurso conservacionista oficial reproducido en memorias presidenciales e institucionales, al describir el desenvolvimiento de prácticas humanas contradictorias con el mismo en el espacio geográfico y temporal de estudio.

La primera parte del artículo analiza las principales causas para la nacionalización de la Hacienda "El Murciélago", su procedimiento e implicaciones socio y geopolíticas, así como la posterior segmentación de este espacio con fines de conservación y desarrollo productivo local durante la administración Carazo Odio (1978-1982). En su segunda parte, se evalúa la incipiente gestión del SM como parte integrada del PNSR en la administración Monge Álvarez (1982-1986) y el uso estratégico de su territorio marítimo, aéreo y terrestre para la activación de los protocolos de seguridad nacional y defensa fronteriza sin desdeñar las consecuencias ambientales de las prácticas 
humanas licenciadas allí con venia burocrática en dicho período. Finalmente, la tercera parte establece una continuidad del proyecto geopolítico anterior durante el primer año de la administración Arias Sánchez (1986-1990), pese a un viraje discursivo de este gobernante ("pacifismo") respecto al de su antecesor ("neutralidad perpetua").

\section{EXPROPIACIÓN DE HACIENDA “EL MURCIÉLAGO” EN LA ADMINISTRACIÓN CARAZO ODIO (1978-1982): UN PROYECTO CONSERVACIONISTA Y DE ASENTAMIENTO HUMANO.}

Ante la maduración del conflicto sociopolítico nicaragüense hacia finales de 1978 , la presión diplomática multilateral ${ }^{8}$ para la caída del régimen somocista desencadenó amenazas por parte del dictador basadas en una inminente invasión a Costa Rica9. Estas fueron apenas contendidas por los protocolos de cooperación internacional en el campo militar ${ }^{10} \mathrm{y}$ de seguridad fronteriza del país, y a la vez lograron que fuera percibido como contradictorio tanto para las autoridades políticas costarricenses como para la opinión pública nacional que la familia Somoza continuara con importantes activos en el territorio nacional. Como lo establece Edelman (1994, pp. 27-28), el vasto territorio de "[El Murciélago llamó una] mayor atención negativa en Costa Rica...debido a su larga costa y a la cercanía de la frontera". Sobre su suelo los Somoza habrían invertido en las sociedades anónimas Murciélago Limitada y Compañía Agropecuaria La Esperanza S.A, postergando sus intereses geopolíticos tendientes a evitar ataques reaccionarios al régimen dictatorial desde Costa Rica y augurando una continuidad de las incursiones nicaragüenses ocurridas fuera del control migratorio costarricense (Edelman, 1998).

Inclusive en dicho contexto se publicaban las denuncias del diputado alajuelense Óscar Rodríguez en el periódico La Nación: "dos de las cañoneras de la Guardia Nacional de Nicaragua intimidaron a los pescadores nuestros y turistas que estaban en la costa de Guanacaste" ("Aprobada la expropiación", 1979, s.p.). El mismo Edelman $(1994,1998)$ enumeró otras violaciones previas a la soberanía costarricense desde mediados de los años 60 que terminaron de agudizar el descontento popular por Somoza en la década siguiente. Tales violaciones van desde el uso indiscriminado de una pista de aterrizaje para vuelos no reportados como afrenta al tráfico aéreo del país, la continuidad de prácticas contrabandistas y del flujo de migrantes nicaragüenses indocumentados (muchos de ellos absorbidos como fuerza de trabajo de la hacienda antes que nacionales), hasta entrenamientos militares a exiliados cubanos con pretensiones bélicas contra el régimen castrista en 1971 (Edelman, 1994, pp. 26-27).

Debido al clima de tensión suscitado ante la continuidad de afrentas a la soberanía nacional y el prevaleciente sentimiento antisomocista en el país, el expresidente Carazo aceleraría los trámites legales y de avalúo para la expropiación que había decretado el 18 de septiembre de 1978 de la Hacienda ubicada en La Cruz de Guanacaste (Evans, 1999, p. 202). Más adelante el gobernante escribiría: 
"un hombre que mostraba tal desprecio por el honor, la dignidad y la soberanía de Costa Rica, no merecía ser propietario, siquiera, de un centímetro cuadrado de nuestro suelo" (Carazo, 1989, p. 292). Para dicho año inclusive eran patentes campañas de recolección de fondos que involucraban a la sociedad civil costarricense para el pago de la expropiación: en la prensa de la época se informaba que "se emplear[ía] parte del dinero que Radio Monumental esta[ba] recogiendo...para la mencionada expropiación" ("Aprobada la expropiación", 1979, s.p.).

Lo cierto es que desde el 16 de mayo de 1978 se encarga a miembros del gabinete ministerial de la administración Carazo el acuerdo para la compra definitiva con fondos públicos y a la Procuraduría General de la República (PGR) revisar la legalidad del acto expropiatorio por parte del Estado de las fincas de "El Murciélago" (Archivo Nacional de Costa Rica, 1978a). Dos días después, el primer órgano solicita al Instituto de Tierras y Colonización (ITCO), a la Dirección General de Tributación Directa (DGTD) y a los bancos nacionales un peritazgo para conocer el valor real del terreno hacendario (Archivo Nacional de Costa Rica, 1978b). El 16 de junio del mismo año se crea una comisión a cargo del Ministro de Agricultura y Ganadería (MAG) Hernán Fonseca Zamora (1930-2011) para realizar un informe de avalúo completo, integrando a las instituciones antedichas (Archivo Nacional de Costa Rica, 1978c).

Paralelamente, y a razón de la necesidad de elevar la expropiación a rango de ley dado el consenso generalizado respecto a la política de seguridad antisomocista del momento, el Sr. presidente de la Comisión de Gobierno y Administración de la Asamblea Legislativa Cristian Tattenbach Iglesias (1924-2007) solicita vía telegrama un avalúo especial completo a la DGTD de las 10 fincas que componen "El Murciélago" (Archivo Nacional de Costa Rica, 1978d). El diputado lo recibiría el 26 de junio de 1978. Este documento consideraba el valor del terreno, construcciones, instalaciones y maquinaria en $\mathbb{Q} 24.761 .728$ correspondientes a un área de 15.757 hectáreas ${ }^{11}$, según datos del Registro Público (Archivo Nacional de Costa Rica, 1978d).

Como muestra de una actuación administrativa totalmente independiente en los procedimientos para la expropiación por parte del Poder Legislativo y del Ejecutivo, se establece en el Consejo de Gobierno el 30 de noviembre que "el valor de la Hacienda el Murciélago se fijó en doce millones doscientos noventa y un mil colones" (Archivo Nacional de Costa Rica, 1978e). Es decir, apenas la mitad del valor previamente presupuestado para el congresista. Esto sería reflejo de una sobreestimación del precio hacendario en primera instancia al presupuestarse junto con el valor del largo territorio costero. Es decir, éste último debía restársele al valor total del conjunto de terrenos sujetos a nacionalización, en tanto ya era de propiedad estatal (área pública según la legislación nacional vigente). O bien, dicho valor cercano a los $\mathbb{C} 24$ millones sería resultado de un depurado y por tanto inadecuado peritaje que posiblemente ignoró la extensión territorial indicada en fuentes registrales o en el mismo plano de la Hacienda, el cual estaba en poder de su concluyente administrador el Sr. Hilario Silva (Archivo Nacional de Costa Rica, 1978d). Lo patente fue que al final del proceso de nacionalización sería resarcido un valor inferior, pero muy cercano al recibido por Tattenbach. 
Desde el 13 de setiembre de 1978, con el Decreto Ejecutivo No 9119-G, el Consejo de Gobierno habría ordenado formalmente el acto expropiatorio que recuperaría a "Murciélago" como bien demanial o de dominio público (Decreto Ejecutivo, 1978). Aunque sería hasta el 11 de enero de 1979 se estudiaría en el seno de dicho Consejo, durante un contexto de grandes dificultades financieras por la crisis petrolera de finales de la década de 1970, el mecanismo de pago para la expropiación. Estaba entre las opciones sugeridas por la Contraloría de la República un presupuesto extraordinario de la República y un préstamo de RECOPE (Archivo Nacional de Costa Rica, 1979a). En el acuerdo de gobierno de dicha fecha, se le insta a la Procuradora General la redacción de otro que permita la toma oficial de la hacienda, así como la consolidación del pago gubernamental correspondiente (Archivo Nacional de Costa Rica, 1978d). No obstante, es a través de un oficio del mismo Carazo Odio, enviado el 2 de septiembre de 1980 al MAG, que se conoce que el financiamiento para la compra del SM devino de bonos de parques nacionales más allá de las opciones estudiadas (Archivo Nacional de Costa Rica, 1980a).

La Asamblea Legislativa en terminaría por reforzar el decreto $\mathrm{N}^{\circ}$ 9119-G promulgado con la aprobación de la Ley $\mathrm{N}^{\circ} 6279$. Con esta se declara de interés público el territorio hacendario, formalmente expropiándose e inscribiéndose en los registros públicos por parte de la PGR. Finalmente, se establece como una ampliación del PNSR a cargo de la administración del MAG. A la vez quedaría esta extensión de suelos sujeta a titulaciones gratuitas del ITCO a campesinos de la zona y a las delimitaciones que el Poder Ejecutivo estableciera como convenientes (Ley de Expropiación de Hacienda Murciélago para Parque Nacional Santa Rosa, 1979, arts.1-5, s.p.).

Es así como, el 21 de junio de 1979 se informa durante las sesiones de coordinación del Poder Ejecutivo de la presencia oficial del presidente en la hacienda "El Murciélago". Esto en representación de la nación para ultimar los procedimientos legales relativos a su toma de posesión e inmediatamente declarándose parte de ésta con el nombre de "Asentamiento Campesino Juan Santamaría" (Archivo Nacional de Costa Rica, 1979b). Precisamente, con fecha de un día después, se lee en la carta informativa de publicación periódica "Costa Rica Puede" emitida por el Ministerio de Cultura, Juventud y Deportes (MCJD) que:

En un acto en el que participaron el Presidente de la República, Rodrigo Carazo, el Ministro de Seguridad Pública y otros funcionarios y jueces de la república, el Gobierno de Costa Rica tomó oficialmente posesión de las 16.075 hectáreas de tierra que forman la Hacienda El Murciélago, anteriormente propiedad del General Anastasio Somoza Debayle, de quien fue expropiada. La expropiación hecha por razones de «utilidad pública», se formalizó mediante el pago de 22 millones de colones, parte de los cuales fue aportado por la ciudadanía costarricense mediante colecta popular. La extensa finca servirá para que, en parte de ella (3.500 hectáreas) se dé cabida a un asentamiento campesino en donde 150 familias de la región obtendrán tierras de labrantío para su explotación y aprovechamiento. El asentamiento campesino fue bautizado con el nombre Juan Santamaría. El resto de la finca será dedicado, parte a reserva forestal y parte a la ampliación del Parque Nacional Santa Rosa, como una gran reserva biológica nacional. Con este 
acto se cumple una de las mayores aspiraciones del pueblo costarricense que ha deseado, por mucho tiempo, la nacionalización de una importante zona de territorio nacional que se había prácticamente enajenado al caer en manos de la familia Somoza de Nicaragua. (Archivo Nacional de Costa Rica, 1979c).

De esta forma, el Gobierno de Costa Rica, satisfizo - relativamentelas demandas locales con el otorgamiento de tierras, dirimiendo los históricos conflictos persistentes por las mismas y brindando una contención económica a las familias que aún laboraban en los confines hacendarios ${ }^{12}$. También con dicha toma oficial se abonaría exitosamente a aquellas presiones de los medios de comunicación y de la opinión pública nacional con un matiz nacionalista y de reafirmación de la soberanía nacional (Evans, 1999). Esto se vería particularmente con la remembranza presidencial y previamente periodística de la histórica Campaña Nacional de 1856 contra las fuerzas de expansionistas estadounidenses conocidas como "filibusteros", quienes ocuparon militarmente a Nicaragua y que consideraron que el largo territorio fronterizo de Guanacaste le pertenecía a este último país, amenazando con recuperarlo (Fallas, 2015, p. 60).

En dicho proceso, el presidente Juan Mora Porras (1814-1860) convocaría a un ejército compuesto por "labradores y artesanos" que defendería finalmente la integridad del territorio nacional, siendo el mítico soldado Juan Santamaría (1831-1856) parte de éste y sobre todo un recurso táctico decisivo y "heroico" en la Batalla en Rivas de abril de 1856 (Fallas, 2015). Su nombre quedaría sellado en la simbología del discurso oficial desde la Costa Rica liberal decimonónica, en la cultura popular del país y constantemente referido por gobernantes costarricenses durante el siglo XX como representativo de la sencillez popular, de la libertad y de la defensa del orden establecido en la vida nacional (Cabrera, 2015; Fallas, 2015; Palmer, 2007). Esta vez, 123 años más tarde del sacrificio de Santamaría para quemar el "Mesón de Guerra" ocupado por los filibusteros en Rivas (Molina, 2000,pp. 33-37), el presidente Carazo designaría al nuevo sitio agrícola (ubicado al margen del río Cuajiniquil y que serviría de extensión a los pocos caseríos del poblado de mismo nombre) con el emblemático apelativo.

La recuperación de la superficie tendría una significancia especial para la sociedad costarricense, debido a que ocurriría muy cerca del lugar donde se gestó otro triunfo nacional durante la guerra contra los filibusteros: la Batalla de Santa Rosa. Así, la administración Carazo reinvertiría el control estratégico de una importante porción territorial en el Pacífico Norte limítrofe, al tiempo que otorgaría una ampliación de la conservación ambiental iniciada en 1966 con la declaración del Monumento Nacional de la Casona de Santa Rosa y luego con la instauración oficial del PNSR en 1971 y ampliaciones subsiguientes (de 1977, 1982, 1987, 1990 y 1991) (Quirós, 2017, p. 99). Sin embargo, este resultado no fue del todo expedito y el nuevo rol que las autoridades políticas le asignarían al SM, así como la distribución exacta del territorio expropiado generarían incertidumbre a varios sectores del país interesados, entre ellos grupos conservacionistas y los mismos administradores del PNSR al finalizar la década de 1970. 
De acuerdo con Mora (citado en Evans, 1999, p. 204) ${ }^{13}$, estos últimos auguraban no dificultades logísticas para administrar adecuadamente el territorio, a razón de la lejanía de la península anexada con el cuerpo principal del parque, lo que condicionaría sobre todo la función de patrullaje a este nuevo vasto espacio. También se presagiaba una "agenda oculta" mediante la cual la conservación del SM servía de excusa, ya no para una estrategia defensiva ante los arrebatos de Somoza, sino una que involucraba un activo entrenamiento a sandinistas por parte de oficiales costarricenses (Ugalde \& León citados en Evans, 1999, p. 204) ${ }^{14}$. Este llevaría a una crispación política entre Álvaro Ugalde Víquez (1946-2015), director del Servicio de Parques Nacionales (1977-1979) y el Consejo de Gobierno (incluyendo al presidente Carazo). El primero denunciaría "prácticas de tiro que usaban como blanco árboles y cercas del parque [y que] (...) el superintendente del [mismo] necesitaba permiso de la policía para moverse dentro de él" (Evans, 1999 , p. 5). Esto a través de un acalorado cable o telegrama enviado al Ministro de Seguridad Pública (MSP) Juan José Echeverría Brealey, en el que tildando a los efectivos policiales nacionales de "soldados", solicitaba el retiro de estos fuera del SM en tanto dicha área era de plena jurisdicción y responsabilidad del SPN (Evans, 1999, p. 5). La situación fue tema de abordaje inmediato en el consejo de gobierno, dados los términos de referencia del escrito suscitado en un país que reproducía el discurso antimilitarista y de paz, que si bien tuvo el efecto de un retiro policial y una férrea defensa por parte del MAG a Ugalde "por hacer su trabajo", fregó las relaciones del presidente con este funcionario (fiel defensor de la conservación ambiental a través del $\mathrm{SPN}^{15}$ ) al punto de haber sido señalado en los albores de dicho órgano ministerial como "antipatrótico y traidor" (Evans, 1999, p. 6).

El hecho de que esta agitación gubernamental diera sus efectos se manifiesta por dos razones. La primera, a razón de la necesidad de que los vínculos gubernamentales con el sandinismo (aunque explicados por el antisomocismo de la época) se mantuvieran al margen de un evidente escrutinio público. Esto constituiría una incoherencia que, pese al despliegue de seguridad intensificado en la zona limítrofe, Costa Rica estuviera coludiendo subrepticiamente por la vía armada en la desestabilización nicaragüense desde el propio territorio y destruyendo el mismo entorno dispuesto a ser protegido, a la vez que solicitaba ayuda a nivel internacional para la pacificación fronteriza. De hecho, ninguna de las operaciones realizadas en SM a favor del movimiento guerrillero fue recuperada en el Informe de Labores de los Ministerios de Gobernación y Seguridad Pública de 1978-1979. Esto excepto si las materias de "Guerra de Guerrillas, control de turbas, táctica soldado individual, Amet[ralladora] Browning Fusil M-1 calibre 30", impartidas como instrucción de personal del área de Primera Comisaría y Policía Militar hubiesen sido en "El Murciélago", lo cual no se registra con el debido detalle (Departamento de Servicios Bibliotecarios, 1979, p. 36). Por el contrario, se señalan en el mismo informe una serie de capturas de sandinistas a lo largo y ancho del país con motivo de la llamada "Operación limpieza guerrilleros" 
(Departamento de Servicios Bibliotecarios, 1979, p. 36). Esto lo que ratifica es una contradicción de la política de seguridad fronteriza de la administración Carazo durante el período entre la toma de posesión de la hacienda y la eventual segregación del extenso terreno para los fines indicados anteriormente.

Lo cierto es que aunque los anuarios del Ministerio de Seguridad no ratifiquen las prácticas colaborativas con los revolucionarios nicaragüenses, como lo establece el trabajo de Martínez (2017, p. 184), “el gobierno de Rodrigo Carazo Odio [sí] había permitido que el territorio de Costa Rica sirviera para establecer campamentos del [Frente Sandinista de Liberación Nacional]" y más adelante, licenció que un avión de la Fuerza Aérea Mexicana (el «Quetzalcóatl») que recogía asilados políticos nicaragüenses en Managua hiciera escala en el país, "en donde se otorgaban distintos recursos a los miembros del Frente Sandinista (...). [Una actividad] no posible, de no contar con el apoyo y venia del gobierno de Carazo" (Martínez, 2017, p. 187).

La segunda razón que justifican un cambio hacia la persecución de sandinistas y una expulsión de los entrenamientos con costarricenses en la nueva área protegida (SM del PNSR) tiene que ver con la presión y cabildeo de diversos grupos conservacionistas (algunos de ellos de origen norteamericano) con importantes recursos económicos y gran incidencia dentro del escalafón burocrático costarricense ligado al sector ambiental, por ejemplo, The Nature Conservancy con el apoyo del director Ugalde (Evans, 1999, p. 206). Entre otros nacionales estaban la Fundación de Parques Nacionales (clave para financiar repatriaciones de territorios para su preservación patrimonial en el país), el Centro Científico Tropical (CCT) y la Organización para Estudios Tropicales (OET) (entidades relevantes en la provisión de asesorías técnicas para la toma de decisiones públicas sobre los nuevos espacios protegidos por parte del Estado costarricense). Estos influirían para la cuidadosa delimitación del SM según las intenciones enmarcadas en la fuente oficial citada "Costa Rica Puede" y la misma Ley Nº6279.

El papel de estos grupos emergió como influjo de la pérdida del poder adquisitivo de los ya recortados presupuestos del SPN para la actividad de protección de parques tras un serio escenario de inflación producto de la crisis petrolera de 1979. En palabras de un oficial anónimo del PNSR durante dicha época: "hacía falta el combustible y recursos para el pago de las dietas a los choferes, las unidades móviles estaban deterioradas, algunos programas de atención de visitantes fueron completamente abandonados" (Evans, 1999, pp. 191-192). Es decir, algunas organizaciones aprovecharon las condiciones de emergencia financiera para ejercer presión por una profundización de las políticas de conservación, lo cual fue favorecido por la actitud de la administración Carazo de continuar esta tendencia. El mismo presidente sostenía una valoración positiva hacia dichas políticas incluso con connotaciones religiosas (Evans, 1999, pp. 188-189).

Para él la protección del ambiente se derivaba del mandato cuasi divino de "respeto a todas las formas de vida y su balance" (Carazo, 1989, p. 254). De acuerdo con las memorias de Ugalde: 
La década de los 80, marcó el inicio de un movimiento conservacionista que buscaba soluciones ante la inflación de la que fuimos víctimas durante los primeros seis años de la década. Muchas de las 26 organizaciones de ayuda internacional tales como CIDA de Canadá, DANIDA de Finlandia, GTZ de Alemania, FIINIDA de Finlandia, NORAD de Dinamarca y ODA de Inglaterra, donaron dineros a Costa Rica, con énfasis en proyectos de conservación. Además de éstas, muchas organizaciones conservacionistas apoyaron a nuestro país durante la crisis. Esta nueva fuente de ingresos evidenció la necesidad de establecer la Fundación de Parques Nacionales (FPN), institución a la cual le correspondería la administración de las contribuciones internacionales. Presidida por Mario Boza, la fundación nace en 1979. La respuesta de la FPN ante la crisis económica fue lanzar una campaña de recaudación de $\$ 5,5$ [millones] en un periodo de cinco años. Esta campaña se convirtió en la prioridad número uno de la Fundación y gracias al esfuerzo nacional e internacional, la cifra fue conseguida en 1986, en menos tiempo de lo inicialmente estimado. (Ugalde, 2016, p. 13).

En este sentido fue posible que continuaran los programas educativos, la compra de extensiones de terrenos para el SPN (incluyendo el SM), asesoría y ayuda técnica para el manejo de recursos naturales y forestales (entre ellos, los de reforestación) con una institucionalidad capaz de percibir los flujos de cooperación ambiental (préstamos, becas y donaciones) y canalizarlos para los fines enmarcados. Todo esto tras la fuerte campaña ambientalista engendrada desde la administración Carazo y sobre todo potenciada por el SPN bajo la dirección de Ugalde a partir de 1979. De hecho, la incorporación oficial del SM al PNSR con el Decreto Ejecutivo $\mathrm{N}^{\circ} 12062$-A del 13 de noviembre de 1980 es el que ha permitido que hoy día persistan las siguientes condiciones ambientales:

[el] bosque seco por muchos años se vio amenazado por la cacería, la agricultura, la explotación forestal, la ganadería e incendios forestales, sin embargo todas esas amenazas no fueron suficientemente fuertes para remover por completo la flora y fauna nativa, y por el contrario la restauración de ese bosque está ocurriendo rápidamente, ya que la vegetación y la fauna se están reconstituyendo por sí sola, dispersándose por los campos de pastos, de tal manera que se puedan eliminar las especies introducidas, como por ejemplo el pasto jaragua (Hyparrhenia rufa, desde el este de África) que fue utilizado para alimentar al ganado. (Área de Conservación Guanacaste, 2012b, s.p.)

No obstante, dicha incorporación, fue producto de un tortuoso proceso en el que se debía conciliar el espacio para las prácticas sociales tanto de protección ambiental como de producción agrícola y asentamiento humano en un territorio fuertemente condicionado por sus características geográficas: constantes sequías, topografía quebrada, suelos arcillosos-arenosos de baja fertilidad, etc. Es decir, particularidades propias de una extensión ubicada dentro del Corredor Seco Centroamericano (Díaz, 2019).

Al pasar casi año y medio de la promulgación de la Ley N No279, Carazo ordena al jerarca del MAG, Hernán Fonseca, a elaborar el decreto respectivo "debido al hecho que diversos grupos conservacionistas han pedido efectuar la delimitación" (Archivo Nacional de Costa Rica, 1980b). Esto corresponde sin duda a un fuerte lobby 
tras los flujos de cooperación financiera otorgada. La segregación seguidamente se operativiza como producto de la consideración de 3 propuestas generadas dentro de una comisión integrada por representantes del SPN, el CCT, el Banco Nacional de Costa Rica (BNCR), la Unidad de Suelos del MAG, el ITCO y la Dirección General Forestal (DGF). La primera opción generada por el SPN proponía una demarcación del sector noreste de "El Murciélago" para vocaciones agropecuarias. Esta garantizaba ventajas como: una relativa mayor humedad de la finca, fácil acceso, mejor infraestructura, la posibilidad de explotaciones extensivas (Archivo Nacional de Costa Rica, 1980b). Es por ello que la propuesta contó con el apoyo de la mayoría de los representantes de las instituciones señaladas. En consecuencia, se resuelve con la firma presidencial y del ministro la delimitación oficial correspondiente a la Figura 2 en noviembre de 1980.

En este queda patente como la élite política configura el espacio funcional y la disposición de sus recursos naturales para fines varios a cargo por un lado del ITCO, con la titulación y segmentación de lo que hoy día se identifica con los caseríos conocidos como "Las Parcelas" de Cuajiniquil. Y, por otro lado, a cargo del SPN que fungió como un órgano propositivo en las reformas de protección ecológica, clave en la búsqueda de fondos foráneos para el financiamiento de la conservación en el PNSR y en la misma incorporación del SM, así como en la interconexión entre las autoridades decisoras y el cabildeo conservacionista. Este órgano del MAG terminó dirimiendo ciertas prácticas militares y de explotación por un resguardo del nuevo perímetro del parque con un gran reto en su administración debido a la duplicación de su cobertura. 


\section{CONSERVACIÓN EN LA ADMINISTRACIÓN MONGE ÁLVAREZ (1982-1986): ADIESTRAMIENTO MILITAR EN ZONA PROTEGIDA}

El potencial atractivo turístico del PNSR relativo a su fauna era innegable para las autoridades de conservación a inicios de la administración Monge. Estas mismas registraron "más de 200 especies de aves, tres especies de monos, y gran cantidad de ungulados y murciélagos [que] habitan el área" (Servicio de Parques Nacionales, 1983, p. 3). Igualmente, dimensionaron la extensa sabana y riqueza forestal que le sirve de hábitat a dichas especies: "el Tempisque (...), el Panamá (...) y otros bosques deciduos [como] el árbol nacional de Guanacaste (...) y el Indio desnudo" (Servicio de Parques Nacionales, 1983, pp. 2-3).

A pesar de ello, el Sector Murciélago (de mayor tamaño con 11.600 ha consolidadas frente a las 10.313 ha del Sector Santa Rosa) en 1983 tenía el menor adelanto en términos de la accesibilidad y de los servicios brindados por el Sistema de Parques Nacionales. De los 15 personeros que protegían los recursos del parque, únicamente 5 resguardaban las lides del SN y en general, esta porción del parque no contaba con los "servicios básicos" para visitantes que sí tenía, con gran diferencia, el área relativa al centro histórico del PNSR (Servicio de Parques Nacionales, 1983, pp. 1-2). Esta última poseía diversas facilidades, entre ellas: "áreas de almuerzo, de acampar, acceso a agua potable, servicios sanitarios, baños, miradores, senderos, información por equipo de guías, letreros" (Servicio de Parques Nacionales, 1983, pp. 1-2).

Esto puede explicarse por la preponderancia histórica del Sector Santa Rosa, sobre todo conforme a su "Casona", otrora perteneciente a la Hacienda Santa Rosa y epicentro de la victoria contra el filibusterismo el 20 de marzo de 1856. También porque el SM fue el último en adherirse y su gestión estaba apenas en ciernes. No obstante, en términos presupuestarios, la vigencia de la crisis económica y financiera costarricense, que se agravaría por los compromisos estatales del pago de la deuda externa acumulada, incidirían en la raquítica labor de guardaparques y orientación turística del SM.

El mismo contexto geopolítico internacional se recrudecería con la "doctrina Reagan" en 1983 y el aumento del financiamiento a "la contra" que haría de la zona fronteriza nacional, incluido el SM, un lugar estratégico desde donde incursionar operaciones castrenses. Esto motivará un viraje en torno a un nuevo rol que podría jugar el SM, concerniente a una nueva visión de seguridad nacional de la administración Monge, que como efecto colateral acrecentaría el atraso del fomento turístico en el área.

Precisamente un año antes, de las aproximadamente 3500 ha controladas por el ITCO (para 1982 reformado en Instituto de Desarrollo Agrario) y delimitadas del SM en la Figura 2: unas 10 ha y 7100 m con salida marítima a la Bahía Tomás fueron concedidas para el Ministerio de Seguridad (MS) sin un traspaso oficial a esta institución (Ramos, 2007). Lo cierto es que, a diferencia de la administración Carazo, bajo el gobierno de Monge se incursionaría en el territorio no protegido de "El Murciélago", es decir, el delimitado para labrantío. Esto mediante mecanismos formales de arrendamiento y bajo un acuerdo institucional con el IDA. 
De forma que se aprovecharía la evidente posición estratégica referida cercana a la línea fronteriza y también las instalaciones hacendarias que habían sido expropiadas en 1979 y que históricamente habían albergado fuerzas de seguridad: paradójicamente tanto de la Guardia Nacional somocista en los 60 y 70, como de la guerrilla sandinista y la Guardia Civil costarricense en el ocaso de dicha última década. Entre esas instalaciones se contaba en regulares condiciones la casa principal, la cocina, un campamento, otrora habitación de peones con una galera anexa y un troje con dos departamentos (la mayoría de bahareque y madera) en Puerto Castilla ${ }^{16}$ (Archivo Nacional de Costa Rica, 1978d).

La presencia del MS en "El Murciélago" era parte no sólo de una política de modernización del aparato de seguridad con un remozamiento armamentístico ausente en la administración anterior y un aumento del presupuesto a la cartera ministerial correspondiente (Muñoz \& Romero, 1991, p. 158), sino que ésta también era una exigencia del contexto político centroamericano de intensificación bélica. Al respecto, Costa Rica se encontraba urgido por cooperación foránea para el saneamiento de sus finanzas públicas y de su macroeconomía en general, así como de asistencia técnica e impulso financiero en sus programas de reactivación productiva (Marín, 1993). Lo anterior para reemplazar el agotado modelo desarrollista y de sustitución de importaciones que, aunado al incremento de los precios internacionales del petróleo a finales de los 70 y el cobro de los empréstitos externos por parte de los organismos financieros internacionales, conllevó al país a niveles inusitados de inflación, bajas exportaciones y deuda pública.

Por el otro lado, el mando de la potencia del hemisferio occidental (EE. UU) estaba empecinado con una efectiva limpieza anticomunista en su "patio trasero" y basada en resultados. De ahí una relación quid pro quo entre ambos países durante la administración Monge que significó la materialización de una máxima perenne en la política exterior costarricense indicada por Muñoz y Romero (1991, p. 148), por la cual "los intentos tendientes a aumentar la seguridad externa a menudo dan como resultado el cercenamiento de cuotas importantes de soberanía". Es decir, las estrategias para reducir la vulnerabilidad económica y social del país, en clara época de crisis, necesariamente implicaban la inyección de recursos estadounidenses. Esto sobre todo como medidas remediales y de contención económica ante posibles infiltraciones sandinistas o ante el escenario de que emergiere del descontento popular costarricense y de las golpeadas condiciones estructurales del país, una interiorización de la ideología "de la revolución permanente". Propiamente dichas medidas se aplicarían en los territorios fronterizos más alejados de los principales focos de desarrollo nacional. Por ejemplo, las donaciones de la Agency for International Development (AID) que sirvieron para financiar el "Proyecto Integral de Desarrollo de la Zona Norte de Costa Rica” (Muñoz \& Romero, 1991, pp. 159-160).

Las donaciones y arreglos de pago crediticios con EE. UU se recibieron so pena de una "condicionalidad cruzada" en torno a una reforma política, económica y productiva del país, homologada con la de esta potencia en dos sentidos (Marín, 1993). 
La primera tendiente a una liberalización económica o "modelo hacia afuera" y la segunda basada en esquemas de seguridad con una clara intervención de inteligencia, formación, adiestramiento y armamento norteamericano hacia finales del cuatrienio de 1982-1986.

Es así como, en el último informe de labores del MS a cargo del ministro Benjamín Piza Carranza (1925-2009), se leía:

La defensa de la democracia costarricense no sólo depende de la recuperación económica y del desarrollo social, sino también y de manera fundamental, del grado de seguridad que disfrutamos los ciudadanos, así como de la protección de sus bienes y del mantenimiento de las instituciones. Estos valores básicos de nación costarricense se requieren la organización y el funcionamiento eficaz de un sistema moderno de seguridad nacional, el cual ha sido implantado dentro de la nueva estructura del Ministerio de Seguridad Pública, creando un conjunto de cuerpos policiales de espíritu civilista, debidamente adiestrados tanto en materia policial (Protección de la Ciudadanía) como en la defensa de nuestra Soberanía Nacional, espacio aéreo y aguas territoriales.

Ante la situación que se vive en la línea limítrofe con Nicaragua, por el incremento de los grupos adversos al gobierno de esa nación Seguridad Pública se vio en la urgencia de instalar nuevos puestos de control fronterizo, incluyendo bases navales. (Departamento de Servicios Bibliotecarios, 1986, p. 7)

De hecho, una de las cuatro bases instauradas durante 1982 en el comienzo del gobierno de Monge que se sumaría a la establecida previamente en Puntarenas como parte de dicho "nuevo sistema de seguridad" fue la ubicada precisamente en Puerto Castilla (Departamento de Servicios Bibliotecarios, 1983, p. 16). Luego conocida como Base Naval de Murciélago, se dedicó al patrullaje y vigilancia de la costa y límite marítimo del Pacífico norte. Si bien esta base estaba siendo construida con la colaboración de la comandancia de Guanacaste, muy cercana (al oeste) o casi contigua con el territorio protegido del SM del PNSR, en 1984 "por intervención del señor Director, el [Instituto Costarricense de Puertos del Pacífico] donó un terreno en Puerto Mora [más al norte, al otro lado de la Bahía Cuajiniquil], con el fin de instalar con más comodidades dicha base" (Departamento de Servicios Bibliotecarios, 1984, p. 19). Un año después ya estaba consolidada la Estación Naval en Puerto Mora con "su primordial función [correspondiente a] la defensa fronteriza de nuestras costas, el control y la protección del transporte marítimo y de la flota pesquera nacional en esas aguas" (Departamento de Servicios Bibliotecarios, 1985, p. 27). Esto dejaría a Puerto Castilla habilitada para otro tipo de operaciones nulamente documentadas por los cables oficiales.

Sin duda este despliegue de operativos por mar se sumó estratégicamente a la labor terrestre del Comando Norte, una unidad policial distribuida en 19 puestos de comando y responsable del control de "2.125 kilómetros cuadrados [de territorio nacional], abarcando una extensión lineal de 76,5 kilómetros" (Departamento de Servicios Bibliotecarios, 1986, p. 13). Lo precedente ocurriría en el noroeste fronterizo con Nicaragua durante la administración Monge entre 1985 y 1986 como parte de la llamada por Muñoz y Romero “militarización de la fuerza pública” (1991, p. 165). 
Este comando, aparte de proteger a la población civil costarricense de agresiones en zona limítrofe, se insertaría a colaborar en una política de control inmigratoria de nicaragüenses (véase en la Figura 3).

La unidad abarcaba la seguridad de los principales poblados del cantón guanacasteco de La Cruz: Peñas Blancas, Santa Cecilia, Cuajiniquil y el asentamiento del mismo nombre (Departamento de Servicios Bibliotecarios, 1986, p. 33). La misma se activaría tras las incursiones estratégicas de apoyo a grupos "contrainsurgentes" (tanto estadounidenses, nicaragüenses, como costarricenses) que estaban empecinados en la desestabilización del régimen sandinista. Al mismo tiempo y con relativa cercanía, agentes del Comando Norte, entre otras fuerzas policiales nacionales, recibían constantes capacitaciones y adiestramiento policial-militar en la circunscripción de "El Murciélago" administrado por el MS.

Esto es coincidente con lo que Muñoz y Romero (1991, p. 169) apuntan como "una neutralidad altamente ambigua", en otras palabras, un freno a la elevación a otro estrato bélico de la "guerra de baja intensidad" que Costa Rica venía cultivando desde 1982 y que es consecuente con las maniobras de apersonamiento policial a nivel terrestre, naval y aéreo en el límite fronterizo. Esto al igual que su organización, su capacitación y su equipamiento. Estas estratagemas en lugar de reducirse se intensificaron hacia el final del período presidencial liberacionista, como se mostrará a continuación, lo cual resulta contradictorio con la literal lectura de la Proclama de la Neutralidad Perpetua del 17 de noviembre de 1983 expresada por el presidente Monge:

Según la proclama presidencial costarricense, tanto la Carta de las Naciones Unidas como la Carta de la Organización de los Estados Americanos tienen como objetivos fundamentales afianzar la paz y la seguridad internacionales, prevenir las posibles causas de conflictos entre las naciones y asegurar la solución pacífica de las controversias que surjan entre los Estados.

Además, la proclama señala que la Carta de las Naciones Unidas establece la obligación para los Estados miembros de abstenerse de recurrir a la amenaza y al uso de la fuerza contra la integridad territorial, la soberanía o la independencia política de cualquier Estado.

En base a estos criterios, la proclama señala que la neutralidad de Costa Rica será perpetua, no transitoria, activa y no armada, de acuerdo con los principios del derecho internacional. ("El presidente de Costa Rica anuncia la proclamación de la neutralidad perpetua", 1983, s.p.) 


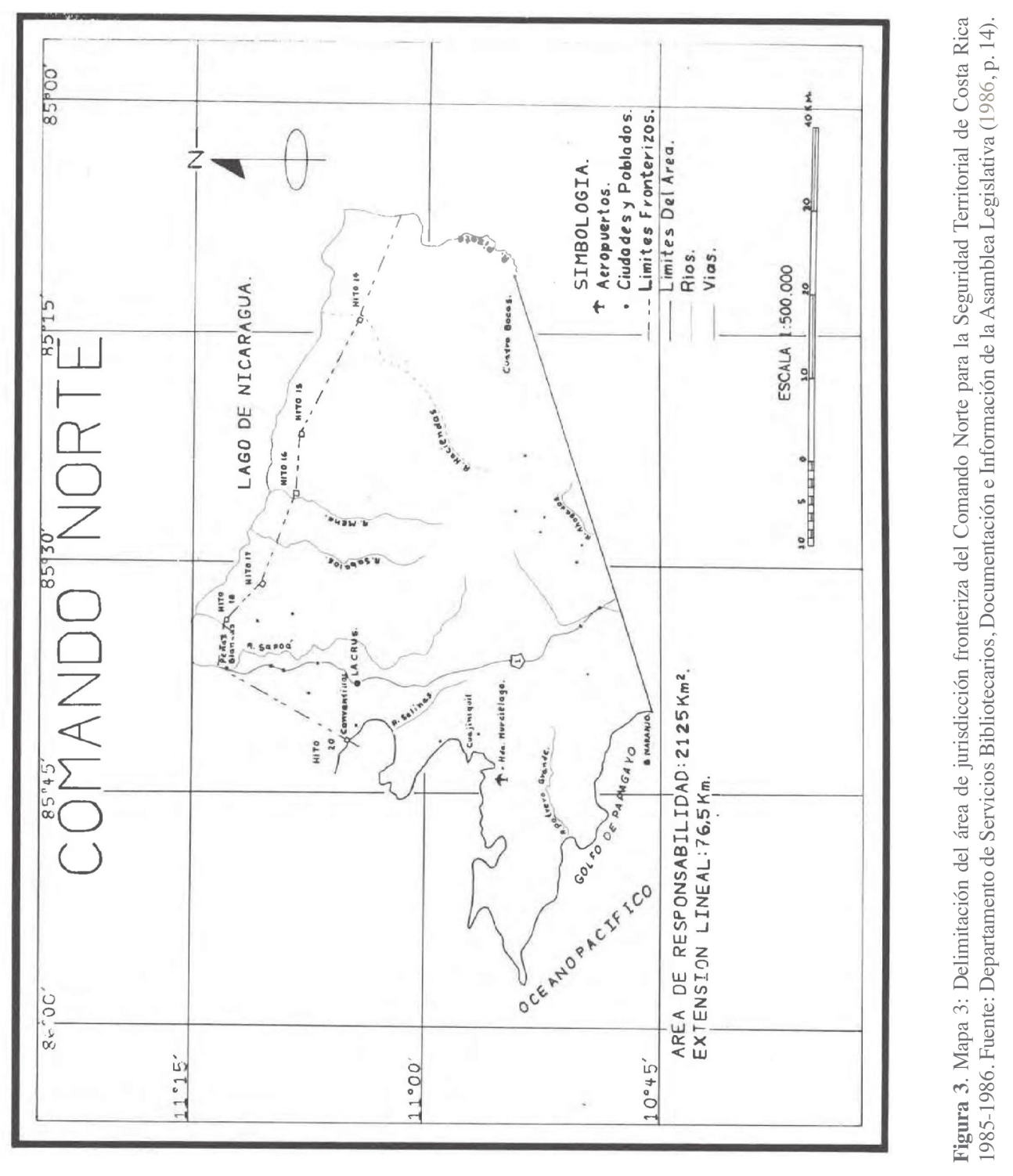


Así, por ejemplo, se registra en un informe (After Action Report: Basic Infantry Training AFZU-SF-C) del Departamento del Ejército de los Estados Unidos, desde el Fuerte Davis en Panamá con fecha del 21 de noviembre de 1985, el entrenamiento de guardias civiles costarricenses como "batallón de reacción inmediata e infantería, para conducir exitosamente operaciones de escuadrón/pelotón (...) enfatizándose tácticas contra guerrillas" (Archivo Nacional de Costa Rica, 1985g, ff.1-4). Según este mismo documento, el entrenamiento fue realizado en "Murciélago", cercano a la villa de Cuajiniquil, con 726 estudiantes y sus áreas de entrenamiento estaban debidamente coordinadas luego de "apropiados arreglos" con la Agencia del Parque Nacional y la Asociación Local de Ganaderos (Archivo Nacional de Costa Rica, 1985g, ff.1-3). Lo que quiere decir lo anterior es que se inmiscuyeron prácticas de formación militar bajo la tutela estadounidense en área protegida, mostrando así un desdén evidente del gobierno por la conservación del SM del PNSR. Esto básicamente por privilegiar una numerosa y posiblemente invasiva faena de adiestramiento.

De hecho, el mismo documento se osa mencionar que una vez habilitada el área de entrenamiento durante su segundo ciclo, tras los permisos respectivos: "se realzó enormemente el círculo de entrenamiento de la pequeña unidad" (Archivo Nacional de Costa Rica, 1985g, f.3). Como lo advierte Reding (1986, p. 308), esto se llevó a cabo durante el período en que el presidente de la república se encontraba liderando una misión diplomática extranjera y por tanto estaba fuera del país, muy poco atento a lo que pasaba en el SM. Es de hecho en ese momento que al escuadrón se le transformó en una unidad especial de combate "entrenado para usar fusiles M-16, ametralladoras M-60, lanzagranadas M2 y M3, morteros y helicópteros" (Reding, 1986, p. 308).

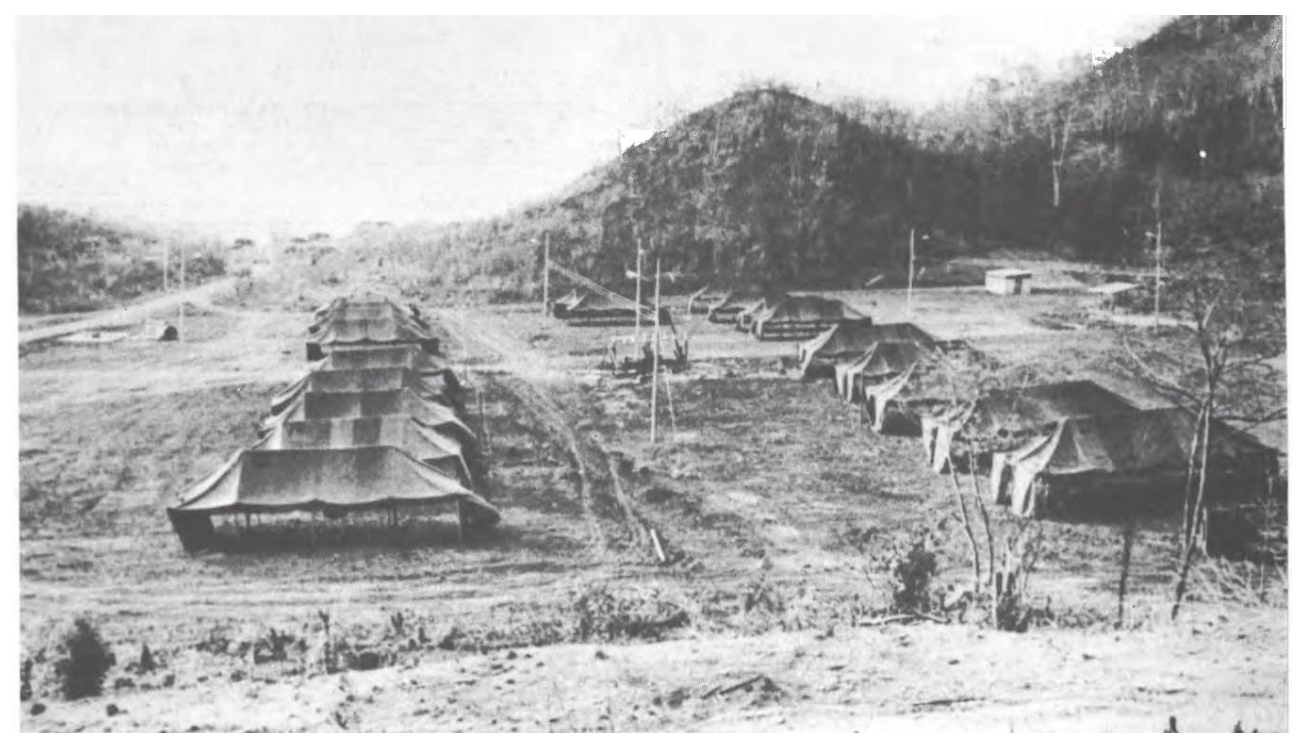

Figura 4. Fotografía 1: Tiendas de campaña que sirvieron de albergue al personal del Ministerio de Seguridad que recibía instrucción en el campo de adiestramiento de Murciélago 1985-1986. ${ }^{17}$ Fuente: Departamento de Servicios Bibliotecarios, Documentación e Información de la Asamblea Legislativa (1986, p. 88). 
En este mismo sentido, Evans (1999) historiografió la evidente desidia de Benjamín Piza, tanto por la "neutralidad perpetua" como por la planificación del SPN en el SM, narrando:

\begin{abstract}
Junto con asesores militares de Alemania Occidental y de Israel, los boinas verdes [Fuerzas Especiales del Ejército de los Estados Unidos] condujeron 10 sesiones de entrenamiento de dos semanas a 1000 guardias civiles en [materia de] sobrevivencia en la jungla, guerra de contra-insurgencia, control de disturbios, y operaciones de patrullaje fronterizo en el frágil ambiente del bosque tropical seco de la Península de Santa Elena. (p. 264)
\end{abstract}

Lo anterior refuerza el evidente desinterés por las categorías de zonificación del PNSR referentes a su uso restringido y protección absoluta. Inclusive, por más que en el regreso de Monge de su viaje por el continente europeo, éste haya reprendido furioso sobre su inferior en comando (Evans, 1999, p. 265). Lo cierto es que hubo una distribución importante de recursos referentes a la cartera de seguridad para el cometido recién citado. Así en una carta oficial de la Oficina de Cooperación de Defensa del Departamento de Estado de los Estados Unidos (en Costa Rica) que enviaría el Teniente Coronel John Taylor, encargado del adiestramiento en el SM el 19 de abril de 1985 al Sr. Piza, se solicita:

\footnotetext{
ajustar las condiciones para el alojamiento de 400 personas en «Murciélago», al mismo tiempo: agua, alojamiento, higiene (letrinas, duchas, lavandería), electricidad, polígonos de tiro y campo para cocinas como prioritarias. Luego, en segundo orden, comprenden dos puentes y el mejoramiento de los campos a nivel permanente. Seguidamente, dos pozos de agua y bombas para tener apropiado suministro, y un mínimo de 25 tiendas de campaña para alojamiento, 400 camas de campaña, mejorar [la] seguridad de la casamata y del campo mismo (...) [Finalmente se informa que los] instructores [norteamericanos que vienen de Panamá] traen 100 rollos de alambre de púas y 3000 sacos de arena. (Archivo Nacional de Costa Rica, 1985d, s.n.f.)
}

Con lo precedente queda claro que las condiciones de las instalaciones del SM cerca de Puerto Castilla devenían en insuficientes para el entrenamiento proyectado de hasta 1000 efectivos policiales costarricenses y que todo este reacondicionamiento de Murciélago significaba una empresa de vital importancia, a tal punto de que el director del campamento tuviese margen de maniobra política para solicitar diversos servicios del MS. Esto aun cuando mucho de los recursos de la cartera de seguridad probablemente provenía de ayuda directa de la potencia norteamericana, de ahí que Taylor no dudara de solicitar tal lista, que incluía algunas enrevesadas encomiendas, entre ellas, obras de infraestructura. De la cita anterior también puede inferirse que el entrenamiento realizado con o por la "Contra" en "El Murciélago", nunca fue lo suficientemente preponderante para superar en número de efectivos al también llamado "Batallón Autosuficiente" de Costa Rica.

Como corolario del pedido, un mes después en un oficio del Viceministro de Seguridad Pública, Johnny Campos Loaiza del 25 de marzo de 1985, se designa al arquitecto Román Acosta Herrera (1952-2015) como "Director y Coordinador para la construcción del «Proyecto de Murciélago»" (Archivo Nacional de Costa Rica, 1985b, s.n.f.). 
El profesional sería reforzado con el personal, los materiales y la alimentación solicitada por los comandantes del campo. En todo caso, ya desde el 17 de abril anterior en una carta del Encargado de Negocios de Estados Unidos George Jones, se conocía de la donación de una suma de \$2 millones para mejorar el montaje del campo de entrenamiento, sobre todo en "barracas de madera para reemplazar las tiendas de campaña que se están usando" (Archivo Nacional de Costa Rica, 1985c, s.n.f.).

Finalmente, la materialización del proyecto de campo de instrucción permitió la consolidación del pelotón (véase Fotografía 1) y de los 28 cursos de adiestramiento ofrecidos por el MS en 1985, "la mayoría (...) fueron impartidos en la Base de Murciélago y por instructores nacionales" (Departamento de Servicios Bibliotecarios, 1986, p.41). No obstante, cabe destacar que el curso de mayor envergadura mencionado tuvo un control vertical por parte de militares foráneos, implicando cesión de soberanía en la toma de decisiones respecto a recursos y personal en un área especialmente sensible como la correspondiente a seguridad nacional.

Un aspecto que debe dimensionarse por sus efectos en el territorio del SM tiene que ver con la insistencia por parte de los comandantes foráneos en "El Murciélago" (entre ellos el mayor Álvarez y el capitán Graves de la Oficina de Enlace Militar del Departamento de Defensa de los EE. UU) por comunicarse con el ministro Benjamín Piza. Desde enero de 1985 le planteaban, mediante la redacción formal de una misiva elaborada por el teniente Taylor que: "el asunto más urgente que se debe coordinar es el permiso para usar zonas adyacentes a Murciélago como áreas de tiro y maniobras (...). Se debe entender que estas zonas representan los requisitos mínimos pero indispensables" (Archivo Nacional de Costa Rica, 1985a, s.n.f.). Es decir, aunque se requería de legitimación para el uso del PNSR para prácticas de infantería ante el limitado y llano espacio con el que contaba el MS, dichas autoridades del SPN terminaron cediendo, de forma que ambos sectores (ambiental y de seguridad) resultaron coludiendo contrario a los principios de la conservación ecológica, los cuales para el gobierno de Monge claramente no tuvieron prioridad. De ahí que el expresidente Carazo terminara considerando en sus memorias que:

\footnotetext{
En la administración que nos sucedió, estos principios se vieron notablemente obstruidos mediante la instalación, en la finca expropiada, de un campamento de entrenamiento militar, manejado por soldados y oficiales del Ejército de los Estados Unidos de América, al que inclusive se prohibió el acceso a los costarricenses. (Carazo, 1989, pp. 297-298)
}

Igualmente, con la presión por el territorio que merecen los entrenamientos de infantería y siguiendo con la tónica de concertar acuerdos de coordinación interinstitucional para incurrir en el territorio del SM: a vísperas de la finalización de la administración Monge se acuerda en la junta directiva del IDA del 18 de febrero de 1986 el arrendamiento de 49 ha de terreno adicionales al MS. Este se ejecutaría "por un canon de un colón (...) [al terreno anexo] al lote (...) que [ya arrendaba en su momento en] el terreno en Hacienda Juan Santamaría" (Archivo Nacional de Costa Rica, 1986a, s.n.f.). 
Este es un importante dato porque ratifica que, aunque se realizaron operaciones contrarias a la idea de un perímetro de prístino ambiente material, las expansiones territoriales del MS no implicaron ni compra de terrenos, ni el territorio protegido perdió su estatus en función de los fines institucionales del MS. Se trataba de permisos interinstitucionales o alquileres patrimoniales de bajo valor los que licenciaban prácticas a lo largo y ancho del SM.

La importancia del SM como terreno estratégico-militar no únicamente afectaba las zonas de pastoreo y las propias de jurisdicción del SPN, sino también los cerros de la Península de Santa Elena y la pista de aterrizaje presente desde los días de Somoza. De esta manera, es aprovechada la altura del primer espacio geográfico para la instalación de un equipo de 10 radios y una repetidora, luego del suministro de la Reserva Nacional a la Reserva de la Fuerza Pública del Ministerio de Seguridad en septiembre de 1985 (Archivo Nacional de Costa Rica, 1985f, s.n.f.). Lo previo probablemente fue parte del "Programa de Soberanía Radiofónica" basado en una interconexión táctica y administrativa entre los distintos puntos fronterizos como acciones de gobernanza comunicativa y de información. También dicho equipo serviría para montar una ofensiva ideológica contra el comunismo y el sandinismo a través de una campaña radiofónica dirigida a campesinos nicaragüenses del sur (Muñoz \& Romero, 1991, pp. 163-164).

Si bien en toda acción estratégica la tenencia de información facilita mejores operaciones militares con los equipos nuevos mejor colocados y con un tiempo de duración en la instalación de hasta 2 meses, se tendría un mejoramiento de la situación reportada por el sargento Collet para el teniente coronel Taylor algunos días antes sobre la Red de Comunicaciones del Ministerio de Seguridad Pública en el campo "Murciélago". Pues éste había detectado una interrupción de las comunicaciones entre las 02:00 h y las 07:00 h, lo cual dejaba en peligro la seguridad de la zona en la noche. Asimismo, el daño del equipo en ese momento pudo haber suscitado filtraciones a la inteligencia nicaragüense y por ende una ventaja al cuerpo militar sandinista sobre las maniobras policiales de Costa Rica en la frontera (Archivo Nacional de Costa Rica, 1985e, s.n.f.). Por último, como lo describía el avalúo de junio de 1978 respecto al terreno de la Hacienda "El Murciélago":

Frente a las costas de la bahía Tomás, tiempo atrás hubo unas salinas (...). Casi frente a las salinas existe un campo de aterrizaje rústico de un kilómetro de longitud por cinco metros de ancho, de balastro, con la suficiente solidez como para permitir el aterrizaje, invierno y verano, de aviones pequeños. En algunos sectores esta pista ha sido invadida por el pasto; es corriente observar animales pastando allí. (Archivo Nacional de Costa Rica, 1978d, f.1).

Dicho mismo espacio fue renovado para la primera mitad de la década de los 80, a tal punto que se convirtió en el único aeropuerto de la jurisdicción territorial aérea del Comando Norte entre 1985 y 1986, como así lo ratifica la Figura 3. De acuerdo con Evans (1999), el aprovechamiento de la pista se constituyó en el principal potenciador de "El Murciélago" como campo de entrenamiento, a la vez como un espacio estrictamente diseñado para lo marcial. 
Esto a razón de la facilidad que permitía la pista para la importación de materiales y combustible. Contar con estos insumos a la vez favorecía un reacondicionamiento de las desgastadas instalaciones hacendarias. El incipiente aeropuerto de hecho arrojaría una función decisiva al posibilitar la introducción de armas compradas para "la contra" con dinero del tráfico de armas y drogas ilegalmente vendidas a Irán por el gobierno de Reagan (caso conocido como "Irán-Contra", "Irangate" o "Contragate") (Evans, 1999, p. 265; Powaski, 2000).

Una serie de factores incidirían en la modernización y remozamiento de la antigua pista de vuelos y aterrizajes. El primero de ellos tiene que ver con la amenaza del Sr. Lewis Tambs (1927-2017), nuevo Embajador de EE. UU en Costa Rica, de cortar ayuda económica al país en caso de no concretarse la susodicha. Otro corresponde con la relativa animosidad de Monge por la reconstrucción, sobre todo, motivado por temores de irrupción sandinista. A la vez hubo una efectiva orquestación tanto de Piza Carranza al frente del MS, los guardaparques del PNSR y la comandancia guanacasteca, con el objetivo de generar una red de apoyo organizacional para que una "empresa maniquî" conocida como Udall Research pudiera trasladar un presunto "contingente de trabajadores, materiales constructivos y máquinas pesadas a través de PNSR" (Evans, 1999, p. 267).

La decisión tendría un nefasto resultado para la integridad del PNSR, incluido el SM. Se reporta una mala praxis ambiental por parte de la empresa, cuyo impacto se resume en: "incendios forestales, caza de venados, consumo de huevos de tortuga, [hasta el] disparo a un tapir" (Evans, 1999, p. 267). La misma noticia salió a la luz pública aunado a la mayoría de los escándalos políticos (nacionales e internacionales) desarrollados en este acápite. Los hechos fueron duramente sancionados tanto por la opinión pública, como por las comisiones investigativas de la Cámara de Representantes de los Estados Unidos y de la Asamblea Legislativa de Costa Rica (Evans, 1999). La reconstrucción de la verdad de los hechos emprendida en colaboración por ambas administraciones concluyó que se impactó seriamente al recurso natural tanto protegido como no protegido del SM en el Pacífico norte costarricense. Sin duda este sería el proceso de destrucción ambiental por vía antrópica más dañino contra el SM durante toda la administración Monge.

\section{CONTRADICCIÓN EN LA ADMINISTRACIÓN ARIAS SÁNCHEZ (1986-1990): PACIFISMO VS UNA BREVE CONTINUIDAD IN SITU DE LOS PROTOCOLOS DE SEGURIDAD EN SU PRIMER AÑO}

El 8 de mayo de 1986 asume el poder por primera vez Óscar Arias Sánchez $\mathrm{y}$, a diferencia de su predecesor Monge, enfoca su política internacional hacia una solución pacífica de los conflictos armados en Centroamérica que llevó a los Acuerdos de Paz de Esquipulas y la adjudicación del Premio Nobel de la Paz en 1987 (Molina \& González, 2015, pp. 257-258). Al mismo tiempo, este 
promovió una política de carácter pacifista y antimilitarista a lo interno del país, que significó la suspensión de las acciones de adiestramiento castrense ejercida por personal militar estadounidense en el SM y el consecuente distanciamiento de la política belicista de la administración Reagan, a raíz del impacto que estaba teniendo la coyuntura centroamericana en general y nicaragüense en particular, en Costa Rica y en el marco del acercamiento que se venía desarrollando entre los Estados Unidos y la antigua Unión Soviética, que pondría punto final a la Guerra Fría un lustro después.

No obstante, en el SM del PNSR, al menos durante el primer año de su administración, se encuentran evidencias de una continuidad en la política de seguridad militar de Monge. La cual asumiría de forma gradual un carácter civil, consolidando las instalaciones del campamento militar en un campo-escuela que sirviese de recinto permanente para la formación policial en apoyo a la Academia de la Fuerza Pública (AFP), Francisco J. Orlich B, bajo el nombre "20 de Diciembre de 1948" (Archivo Nacional de Costa Rica, 1986c, s.n.f.).

Dichas certezas se reflejan en la correspondencia de altos funcionarios del MS, particularmente aquella comunicada por parte de Rafael Méndez Padilla (1938-2015), director de la AFP. Así, en una carta con fecha del 22 de agosto de 1986 y enviada al licenciado Hernán Garrón Salazar (1917-1992), Ministro de Seguridad Pública, el primero le informa sobre las negociaciones que estaba emprendiendo con Rodrigo Chaves Arguedas, Gerente del IDA, para ampliar la pista de aterrizaje de "El Muciélago". Esto sería posible expandiendo la pista de $820 \mathrm{~m}$ a $1520 \mathrm{~m}$ con terrenos adyacentes al noreste si esta institución cedía 8 ha más de terreno al MS. De esta manera, Méndez Padilla estuvo "explicándole la importancia [a Chaves] para defensa del territorio nacional (...) [de las] prácticas de mapas y brújula con ejercicios de navegación diurnos y nocturnos [allí proyectadas]" (Archivo Nacional de Costa Rica, 1986c, s.n.f.).

Más adelante, en la misma comunicación, Méndez notifica un deslinde ya consolidado, pero insuficiente de hasta 59 ha al MS que "por su topografía profunda y desigual sería de gran utilidad para ejercicios de infantería, además, por su ubicación y altura en relación al Campo Escuela. [Se podrían] establecer puntos de alerta, vigilancia y control con lo cual aumentaría la seguridad en toda el área" (Archivo Nacional de Costa Rica, 1986c, s.n.f.). Ante esto solicita a Garrón, por consejo de Chaves, enviar nota al Presidente Ejecutivo del IDA, en su momento Sergio Quirós Maroto (1922-2015), para solicitar formalmente la ampliación del área de 59 ha cedida a unas 80 ha necesarias para las operaciones señaladas (Archivo Nacional de Costa Rica, 1986c, s.n.f.). En este sentido, todavía la conflictividad en Nicaragua suscitaba acciones estratégicas con acento castrense por parte de la jerarquía institucional del MS pese al cambio de gobierno durante 1986.

Más explícitamente, dos meses después, el 11 de noviembre de 1986 Méndez escribiría: "lasituaciónenlafronteranorteescríticayvamosanecesitarpersonalaltamente calificado en operaciones militares" (Archivo Nacional de Costa Rica, 1986e, f.2.). 
No en vano también, desde el 28 de julio del mismo año, se había solicitado al coronel Guido Bolaños, Director General de la Fuerza Pública, divulgar una circular con la cual se prohibiera con absoluta restricción el ingreso al campo escuela en "el Murciélago" con fines de recreo (Archivo Nacional de Costa Rica, 1986b). Más adelante, la documentación reflejaría una distensión de la zona en cuanto a lo militar, siendo el tema del remozamiento de las instalaciones del campo un tema de discusión, pero respecto a su orientación educativa, y se indicaría un abandono progresivo de personeros de seguridad en los puestos del Comando Norte para la asistencia en el campus “20 de Diciembre de 1948” (Archivo Nacional de Costa Rica, 1986d, s.n.f.).

\section{REFLEXIONES FINALES}

El trabajo muestra al territorio del Sector Murciélago del Parque Nacional Santa Rosa no solamente como una zona protegida con remanentes de bosque tropical seco y especialmente relevante por su resguardo de los ecosistemas del Pacífico Seco, sino también como un espacio de poder, que condicionado por su situación limítrofe y el contexto geopolítico centroamericano e internacional, evidenció su importancia en términos del contexto histórico y político del período investigado. Dicho sea de paso, este espacio sufre una transfiguración funcional como resultado de las decisiones de las cambiantes élites políticas costarricenses. También cambia como producto de su importancia estratégica en términos comerciales y de localización limítrofe. Inicialmente con antecedentes de control y disputa territorial por parte de élites políticas nicaragüenses y sus partidarios políticos, debido a la presencia de los intereses de la dictadura somocista y la consecuente conformación de una especie de enclave en este territorio fronterizo hasta 1978. En dicho año la administración Carazo decide expropiar la hacienda y, con ello, erradicar la presencia de una dictadura que sería finalmente apartada del poder por el proceso revolucionario nicaragüense un año más tarde.

La radicalización del proceso revolucionario sandinista y el ascenso al poder de Ronald Reagan en los Estados Unidos significó el comienzo de una nueva etapa de tensiones fronterizas entre Costa Rica y Nicaragua debido al apoyo de la administración Monge a la fuerza paramilitar antisandinista de "la contra". Ante un hipotético escenario de incursión militar por parte del gobierno sandinista en el país, dicha administración autorizó la presencia de personal militar estadounidense y el establecimiento de un campo de entrenamiento militar en parte de los terrenos de la expropiada Hacienda "El Murciélago", que tenían como fin original la fundación de un asentamiento campesino.

Tras la salida de los asesores militares estadounidenses y una vez superado el conflicto armado en Nicaragua, el MS mantuvo el campo de entrenamiento para la formación de los efectivos de la Fuerza Pública, función que cumple hasta el presente: "la base policial cuenta ahora con tres aulas, un salón con capacidad para 
albergar hasta 700 policías. Además, hay un comedor, casas para los instructores y una oficina donde guardan el arsenal conformado por proyectiles, revólveres y ametralladoras M-16" (Moya, 2007, s.p.). Finalmente, la administración de Carlos Alvarado (2018-2022) oficializó de jure, el 24 de mayo de 2018 mediante la firma de la Ley $\mathrm{N}^{\circ} 9552$ decretada por el Poder Legislativo el 30 de abril de ese mismo año, la ratificación de "Murciélago" como un espacio de formación policial civilista y comunitaria. Aunque esto sucedió hasta 40 años después de la ocupación de facto inicial de dichas instalaciones por parte de funcionarios estatales costarricenses, se comprende ahora la "sede del Centro de Formación Policial Murciélago" como parte de la Academia Nacional de Policía (elevada a rango de ley a través de este mismo marco normativo) (Ley de Creación de la Academia Nacional de Policía, 2018,p. 1).

De esta forma, el SM se consolida como parte fundamental del PNSR y se ha constituido en un bastión de la conservación de la zona de vida de bosque tropical seco; mientras que las tierras en las que se encuentra la Academia Nacional de Policía contribuyen como área de amortiguamiento de esta zona protegida, debido a la presencia de remanentes de dicho ecosistema dentro de su perímetro. Esto en conformidad con las políticas conservacionistas impulsadas por el Estado costarricense a partir de la década de 1990 y que han permitido reforzar la imagen de Costa Rica como un país defensor del medio ambiente a nivel internacional. Esta imagen y las políticas conservacionistas que la fundamentan no han estado exentas de contradicciones. Las mismas se hicieron presentes en los inicios del SM al pasar la protección del ecosistema del bosque seco a un segundo plano debido a los factores geopolíticos que favorecieron la presencia militar estadounidense y su labor de adiestramiento de la policía costarricense en esta porción del extremo noroccidental de Costa Rica.

\section{AGRADECIMIENTOS}

La presente investigación fue realizada en el marco del Programa Estudios Sociales de la Ciencia, la Técnica y el Medio Ambiente (PESCTMA, 805-A4906) y del proyecto "Funding proposal for the advancing development and climate change resilience in the Central American Dry Corridor: translating science into policy in Guanacaste, Costa Rica, and interdisciplinary, international collaboration" (UCREA, 805-B7-286) del Centro de Investigaciones Geofísicas (CIGEFI) de la Universidad de Costa Rica. Los autores también agradecen al personal del Archivo Nacional de Costa Rica por su colaboración en la búsqueda de fuentes documentales para la elaboración del presente artículo. Así como a la geógrafa Paula Marcela Pérez Briceño y al asistente Jasson Mora Mussio por su apoyo en la confección del Mapa 1 (ambos del CIFEGI). 


\section{NOTAS}

1 “Más del 25\% del territorio nacional desde 1969” (Evans, 1999, p. ix).

2 "Se define como bosque seco tropical, [la zona de vida] caracterizad[a] por soportar una larga estación seca (seis o siete meses al año), con vegetación que pierde las hojas durante la época seca, con fuentes de agua muy escasas" (Quirós, 2017, p. 102).

Destaca propiamente en el SM, hacia su lado oeste sobre Fila La Guitarra y sus contornos, el dominio de un remanente singular de 4529,7 hectáreas de "bosque seco enano" o "bosque de bonsai" caracterizado por presentar especies típicas de una zona de vida de "bosque nuboso" pero en una de las zonas más secas de Costa Rica (Vargas, 2016). De acuerdo con el Área de Conservación Guanacaste (2012a, s.p.): “debido a su aislamiento y por la naturaleza del terreno, este parche de bosque es de los más prístinos e intocados de Centroamérica. En las cimas de estos cerros hay acumulación especial de nubes que crean vegetación siempreverde". Lo anterior "se debe a que las nubes provenientes del Caribe chocan contra los cerros de la península [de Santa Elena] y los vientos provenientes de la costa pacífica chocan contra esta cortina de nubes, provocando que la cubierta nubosa se estacione sobre esta área y generando condiciones aptas para estas especies" (Vargas, 2016, p. 74).

Localizada en el Pacífico norte costarricense, específicamente en lo correspondiente hoy día con la circunscripción territorial del distrito de Santa Elena en La Cruz de Guanacaste. La hacienda colindaba al norte con el Golfo de Santa Elena, al sur con la Compañía del Desarrollo de Santa Elena S.A. (actualmente parte del Área de Conservación Guanacaste tras un arbitraje internacional entre la República de Costa Rica y el propietario estadounidense Joseph Hamilton en el año 2000), al este con el Río Cuajiniquil y al oeste con el Océano Pacífico (Archivo Nacional de Costa Rica, 1978d, f.0).

Aunque los orígenes de las apropiaciones de tierras y negocios transfronterizos de la familia Somoza se remonten a los años 30, es en 1962 que con la ayuda de la familia del expresidente costarricense Teodoro Picado Michalski (1900-1960), dadas las buenas relaciones entre ambas élites a nivel personal y político desde la década de 1940, Anastasio Somoza Debayle se convertiría en presidente de dos de las sociedades anónimas que abarcaban el territorio del Sector Murciélago, apropiándose seguidamente en 1963, y a título personal, de la mitad de las acciones correspondientes a dichas empresas (Edelman, 1998, pp. 269-270; Edelman, 1994).

Con antecedentes de intentos para derrocar a los Somoza en 1944, en 1959 y 1960 organizados desde Costa Rica, el hecho de que varios líderes exiliados nicaragüenses estuvieran adquiriendo terrenos cercanos a la línea limítrofe entre países (como Indalecio Pastora dueño de Hacienda Verdún o el general disidente Carlos Pasos dueño de las haciendas de Paso Hondo en Cañas en 1957 y la de Santa Rosa en 1958, en La Cruz) motivaba un interés especialmente geo-estratégico para su contención desde el mismo territorio costarricense, lo cual explicaba el interés de los Somoza y aliados (tanto costarricenses como nicaragûenses) por invertir cercanamente a dichas propiedades (Edelman, 1998, pp. 268-269).

$7 \quad$ Si bien la totalidad de fincas estaban inscritas en el Registro Público de la Propiedad a nombre de Somoza Debayle en 1962, ya para 1979, con el objetivo de guardar el anonimato y evitar las expropiaciones, eran otras personas, a menudo familiares nicaragüenses o simpatizantes del Partido Liberal Nacionalista (PLN) de Nicaragua, las que aparecían a cargo y en representación de "El Murciélago" (v.g. un primo del dictador, Alberto Bermúdez y/o el representante Renaldy Gutiérrez Solano) (Edelman, 1998, pp. 269-273). 
El expresidente Carazo Odio expresó en sus memorias que además de convocatoria al Tratado Interamericano de Asistencia Recíproca (TIAR) mediante el cual países miembros pueden apoyar la defensa legítima de otro ante una amenaza bélica: "todos en el gobierno sabíamos que la amenaza persistía y hacíamos todo lo posible para asegurar la defensa; seguíamos negociando en la OEA para lograr una resolución que terminara con el conflicto, nos manteníamos en permanente relación con la Embajada de Estados Unidos, puesto que ellos nos habían comunicado su decisión de «sacar» a Somoza: decían que «lo harían cuanto antes»" (Carazo, 1989, p. 300).

Tanto Somoza lo expresó por conferencia de prensa que fue retrasmitida públicamente en Costa Rica, como el Gobierno de Carazo Odio estaba informado por cinco fuentes o conductos oficiales de la invasión y represalias que tomaría el dictador contra Costa Rica el 27 de diciembre de 1978 a las 7:00 pm (Carazo, 1989. p. 292).

En el libro Insurrección en Nicaragua: la Historia no contada de Julio Suñol (1932-2011), se detallan las memorias del Ministro de Seguridad de la administración Carazo, Juan José Echeverría Brealey. Las mismas son citadas por Carazo sobre la cooperación militar del Presidente de Venezuela Carlos Andrés Pérez (1922-2010) y del líder de facto de Panamá Gral. Omar Torrijos (1929-1981) como respuesta inmediata a los presuntos ataques somocistas del 27 de diciembre de 1978 a suelo costarricense. El primero dispuso "una flotilla de aviones Mirage que (...) estaban acantonados en Maracaibo, aproximadamente a 55 minutos de Managua" y el segundo "ofreció enviar por aire un grupo de soldados, como adelanto a la tropa que para ayudar a Costa Rica estaba dispuesto a mandar por tierra, y ordenó que un fuerte contingente se trasladara ese mismo día hasta la Provincia de Chiriquí" (Carazo, 1989, p. 292).

11 De acuerdo con el plano ubicado en la oficina de la Hacienda, su área era de 16.431 ha; no obstante, ante anomalías en su catastro y la muy posible (errada) inclusión de la faja costera de $200 \mathrm{~m}$ de propiedad del Estado, la DGTD determina como registradas únicamente las hectáreas establecidas por el Registro Público (Archivo Nacional de Costa Rica, 1978d, f.1).

Si bien hubo una repartición de tierras y otorgamiento de titulaciones por parte del ITCO a alrededor de 100 familias, luego de la expropiación, esta labor no fue del todo satisfactoria para los lugareños, de acuerdo con fuentes orales. Entre ellas, el testimonio de Manuel Alán, comerciante vinculado a la zona desde 1972, quien fue entrevistado por Ronald Díaz Bolaños a finales de febrero de 2019 durante la gira de campo a Cuajiniquil del CIGEFI-UCR y cuyas impresiones fueron transcritas por Gabriel Madriz Sojo el 4 de Abril de 2019. En el mismo, Alán aseveró: "pienso que fuimos dichosos [por ser] de los primeros en ser elegidos y haber sido...pero como «conejillo de indias» [del Instituto de Tierras y Colonización o ITCO]. Se cometieron muchos errores y tanto prácticos como administrativos...y a la fecha. Podemos decir que es mediocre el resultado positivo. No hay un buen resultado social-económico de la función del ITCO (...) hoy en día. Hubo mala distribución de tierras, no fue operativa la distribución y no se cumplieron con metas".

13 El testimonio citado por Evans (1999, p. 204) es el correspondiente a José Rafael Mora, director ejecutivo de la Fundación Parques Nacionales (FPN) a inicios de los años 80.

El testimonio citado por Evans (1999 p. 204) es el correspondiente a Álvaro Ugalde (director del Servicio de Parques Nacionales o SPN durante 1977-1979, 1983-1985 y 1991-1993) y a Pedro León (biólogo de la Universidad de Costa Rica y funcionario del SPN a finales de la década de 1970 e inicios de los años 80).

15 A Álvaro Ugalde se le ha reconocido como "padre de los Parques Nacionales de Costa Rica" por su larga trayectoria institucional y activismo político a favor de la protección de los recursos naturales del país (Ugalde, 2016, pp. 5-14). En palabras del Primer Jefe del Departamento de 
Parques Nacionales (luego SPN) y exviceministro Mario A. Boza Loría: "durante todos los años en los que Ugalde estuvo a cargo del Servicio de Parques Nacionales, asumió siempre una actitud de gran defensa de la integridad de las áreas protegidas, obtuvo un gran apoyo internacional, tanto técnico como económico; avanzó en profundizar la aceptación pública de la importancia de proteger y desarrollar el sistema de parques y reservas y logró consolidar técnica, administrativa y financieramente el Servicio de Parques Nacionales" (Boza, 2016, p. 3).

16 Lugar donde se localiza actualmente el Centro de Entrenamiento Policial Murciélago adscrito a la Academia Nacional de Policía del Ministerio de Seguridad Pública.

\section{REFERENCIAS}

Aprobada la expropiación de la hacienda El Murciélago. (1979, setiembre 28). La Nación, s.p.

Archivo Nacional de Costa Rica. (16 de mayo, 1978a). Acuerdo del Consejo de Gobierno, serie Presidencia de la República, expediente $\mathrm{N}^{\circ} 0017$, acta 3, art. 6, acuerdo 1, f.13. Costa Rica: Archivo Nacional de Costa.

Archivo Nacional de Costa Rica. (18 de mayo, 1978b). Acuerdo del Consejo de Gobierno, serie Presidencia de la República, expediente No0017, acta 4, art. 1, acuerdo 1, f.15. Costa Rica: Archivo Nacional de Costa.

Archivo Nacional de Costa Rica. (16 de junio, 1978c). Acuerdo del Consejo de Gobierno, serie Presidencia de la República, expediente $\mathrm{N}^{\circ} 0017$, acta 9, art. 3, acuerdo 1, ff.35-36. Costa Rica: Archivo Nacional de Costa.

Archivo Nacional de Costa Rica. (26 de junio, 1978d). Telegrama de avalúo espacial Nº16.694 V.E de la Sección de Avalúos de la Dirección General de Tributación Directa, serie de Presidencia de la República, expediente No0098, ff.0-18. Costa Rica: Archivo Nacional de Costa Rica.

Archivo Nacional de Costa Rica. (30 de noviembre, 1978e). Acuerdo del Consejo de Gobierno, serie Presidencia de la República, expediente $\mathrm{N}^{\circ} 0017$, acta 34, art. 19, acuerdo 1, f.178. Costa Rica: Archivo Nacional de Costa.

Archivo Nacional de Costa Rica. (11 de enero, 1979a). Acuerdo del Consejo de Gobierno, serie Presidencia de la República, expediente $\mathrm{N}^{\circ} 0017$, acta 41, art.5, acuerdo 1, f. 220. Costa Rica: Archivo Nacional de Costa.

Archivo Nacional de Costa Rica. (21 de junio, 1979b). Acuerdo del Consejo de Gobierno, serie Presidencia de la República, expediente No0017, acta 64, art. 6, acuerdo 1, f.322. Costa Rica: Archivo Nacional de Costa.

Archivo Nacional de Costa Rica. (22 de junio, 1979c). Carta informativa Costa Rica Puede, serie Ministerio de Cultura, Juventud y Deportes, expediente $\mathrm{N}^{\circ}$ 1318, f.1. Costa Rica: Archivo Nacional de Costa. 
Archivo Nacional de Costa Rica. (2 de setiembre, 1980a). Carta del presidente Rodrigo Carazo al ministro de Agricultura y Ganadería Hernán Fonseca, serie Presidencia de la República, expediente $\mathrm{N}^{\circ} 0345$, s.n.f. Costa Rica: Archivo Nacional de Costa.

Archivo Nacional de Costa Rica. (8 de octubre, 1980b). Delimitación de la Hacienda El Murciélago. Minuta de las reuniones, serie Presidencia de la República, expediente $\mathrm{N}^{\circ} 0345$, ff.1-5. Costa Rica: Archivo Nacional de Costa.

Archivo Nacional de Costa Rica. (30 de octubre, 1980c). Mapa adjunto a la correspondencia del director adjunto del Servicio de Parques Nacionales José María Fernández de la Guardia enviada al ministro de Agricultura y Ganadería Hernán Fonseca que segrega el sector noreste de la Hacienda El Murciélago para actividades agrícolas del área de conservación, serie Presidencia de la República, expediente №345, s.n.f. Costa Rica: Archivo Nacional de Costa.

Archivo Nacional de Costa Rica. (enero, 1985a). Correspondencia del teniente coronel John Taylor, encargado del adiestramiento militar en el SM, al ministro de Seguridad Pública Benjamín Piza en solicitud de permisos para usar áreas protegidas, serie Ministerio de Seguridad Pública, expediente $\mathrm{N}^{\circ} 2190$, s.n.f. Costa Rica: Archivo Nacional de Costa.

Archivo Nacional de Costa Rica. (15 de marzo, 1985b). Nombramiento del arquitecto Román Acosta Herrera como director y coordinador de la construcción del proyecto de campo-escuela en Murciélago por el del viceministro Johnny Campos Loaiza, serie Ministerio de Seguridad Pública, expediente N²190, s.n.f. Costa Rica: Archivo Nacional de Costa.

Archivo Nacional de Costa Rica. (17 de abril, 1985c). Correspondencia del encargado de negocios de Estados Unidos en Costa Rica para recomendación al MSP de gastos de fondos donados en Murciélago, serie Ministerio de Seguridad Pública, expediente №2190, s.n.f. Costa Rica: Archivo Nacional de Costa.

Archivo Nacional de Costa Rica. (19 de abril, 1985d). Correspondencia del teniente coronel John Taylor al ministro de Seguridad Pública Benjamín Piza sobre el mejoramiento de las instalaciones en Murciélago para las capacitaciones militares, serie Ministerio de Seguridad Pública, expediente No2190, s.n.f. Costa Rica: Archivo Nacional de Costa.

Archivo Nacional de Costa Rica. (setiembre, 1985e). Correspondencia del sargento Collet de la Oficina de Enlace Militar al coronel Taylor para reportar interrupciones en las comunicaciones de Murciélago, serie Ministerio de Seguridad Pública, expediente №2765, s.n.f. Costa Rica: Archivo Nacional de Costa.

Archivo Nacional de Costa Rica. (14 de setiembre, 1985f). Correspondencia de la Reserva

Nacional al coronel Carlos Mendieta García de la Reserva de la Fuerza Pública del MSP sobre equipo radiofónico, serie Ministerio de Seguridad Pública, expediente №2556, s.n.f. Costa Rica: Archivo Nacional de Costa.

Archivo Nacional de Costa Rica. (21 de noviembre, 1985g). After Action Report: Basic Infantry Training AFZU-SF-C del Departamento del Ejército de los Estados Unidos desde el Fuerte Davis en Panamá, serie Ministerio de Seguridad Pública, expediente N²765, ff.1-4. Costa Rica: Archivo Nacional de Costa. 
Archivo Nacional de Costa Rica. (4 de marzo, 1986a). Acuerdos de la Junta Directiva del IDA sobre arrendamiento al MSP de 49 ha de terreno en el SM comunicados al ministro Piza, serie Ministerio de Seguridad Pública, expediente N²685, s.n.f. Costa Rica: Archivo Nacional de Costa.

Archivo Nacional de Costa Rica. (28 de julio, 1986b). Oficio AFP 28-480 del coronel y director de la Fuerza Pública Rafael Méndez Padilla con el director general de la Fuerza Pública Guido Bolaños sobre la restricción de acceso al campo-escuela Murciélago con fines recreativos, expediente, $\mathrm{N}^{\circ} 2460$, s.n.f. Costa Rica: Archivo Nacional de Costa.

Archivo Nacional de Costa Rica. (22 de agosto, 1986c). Correspondencia del coronel y director de la Fuerza Pública Rafael Méndez Padilla al ministro de Seguridad Pública Hernán Garrón Salazar sobre un deslinde de tierra en el SM del IDA al MSP, serie Ministerio de Seguridad Pública, expediente, $\mathrm{N}^{\circ} 2460$, s.n.f. Costa Rica: Archivo Nacional de Costa.

Archivo Nacional de Costa Rica. (21 de octubre, 1986d). Correspondencia del coronel y director de la Fuerza Pública Rafael Méndez Padilla con el director general de la Fuerza Pública Guido Bolaños sobre regreso de guardias civiles del Comando Norte a labores de apoyo en la academia de Murciélago, serie Ministerio de Seguridad Pública, expediente, №2460, s.n.f. Costa Rica: Archivo Nacional de Costa.

Archivo Nacional de Costa Rica. (11 de noviembre, 1986e). Correspondencia del coronel y director de la Fuerza Pública Rafael Méndez Padilla sobre su no renuncia al puesto, serie Ministerio de Seguridad Pública, expediente, N²460, f.2. Costa Rica: Archivo Nacional de Costa.

Área de Conservación Guanacaste. (2012a, noviembre 28). Puesto Murciélago [Registro web]. Recuperado de https://www.acguanacaste.ac.cr/biodesarrollo/centro-de-investigacion-y-estacionesbiologicas/puesto-murcielago

Área de Conservación Guanacaste. (2012b, diciembre). Sector Murciélago [Registro web]. Recuperado de https://www.acguanacaste.ac.cr/biodesarrollo/programa-sectores/sector-murcielago

Boza, M. (1984). Guía de los Parques Nacionales de Costa Rica. Madrid: Incafo.

Boza, M. (mayo, 2016). M.Sc. Álvaro F. Ugalde Víquez "Toda una vida dedicada a la conservación de la naturaleza". Revista Biocenosis, 30(1-2), 1-4. Recuperado de https://revistas.uned.ac.cr/ index.php/biocenosis/article/view/1420

Cabrera, M. (2015). Usos políticos de las Batallas de Santa Rosa de 1856 y 1955: o, cómo fallar al inventar tradiciones. Revista Diálogos, 16 especial, 77-97.

Carazo, R (1989). Tiempo y Marcha. San José: EUNED.

Decreto Ejecutivo de Expropiación de las Sociedades Murciélago Limitada y Compañía la Esperanza S.A., $N^{o}$ 9119. (13 de setiembre, 1978). Recuperado del Archivo Nacional de Costa Rica, serie de Presidencia de la República, exp.0098, s.p.

Denyer, P. (2013, enero 31). Geología de Santa Elena [Registro web]. Recuperado de https://www. acguanacaste.ac.cr/investigacion/investigaciones-de-largo-plazo/177-geologia-de-santa-elena 
Departamento de Servicios Bibliotecarios, Documentación e Información de la Asamblea Legislativa. (30 de abril de 1979). Informe de Labores 1978-1979 de los Ministerios de Gobernación y Policía, №350.75M C-1. Costa Rica: Imprenta Nacional.

Departamento de Servicios Bibliotecarios, Documentación e Información de la Asamblea Legislativa. (1983). Memoria 1982-1983 del Ministerio de Seguridad Pública, N³50.75M. Costa Rica: Imprenta Nacional.

Departamento de Servicios Bibliotecarios, Documentación e Información de la Asamblea Legislativa. (1984). Informe de Labores 1983-1984 del Ministerio de Seguridad Pública, N³50.75M. Costa Rica: Imprenta Nacional.

Departamento de Servicios Bibliotecarios, Documentación e Información de la Asamblea Legislativa. (mayo de 1985). Memoria Anual 1984-1985 del Ministerio de Seguridad Pública, No350.75M. Costa Rica: Imprenta Nacional.

Departamento de Servicios Bibliotecarios, Documentación e Información de la Asamblea Legislativa. (mayo de 1986). Memoria Anual 1985-1986 del Ministerio de Seguridad Pública, №350.75M. Costa Rica: Imprenta Nacional.

Díaz, R. (2019). El Corredor Seco Centroamericano en perspectiva histórica. Anuario de Estudios Centroamericanos, 45, 297-322.

Díaz, R., Mora, V., y Madriz, G. (2019). El desenvolvimiento histórico de un asentamiento humano en el Corredor Seco Centroamericano (CSC): Cuajiniquil de la Cruz, provincia de Guanacaste, Costa Rica (1940-2018). En García, C. y Lértora, C. (coord.), Ciencias ambientales y participación ciudadana: Proyecto Ecoepisteme (pp.161-212). Buenos Aires: FEPAI.

Edelman, M. (diciembre, 1994). Un Estado dentro de otro: Las propiedades de los Somoza en el Norte de Costa Rica. Revista de Ciencias Sociales, 66(4), 1994, 21-28.

Edelman, M. (1998). La lógica del latifundio. Las grandes propiedades del noreste de Costa Rica desde fines del siglo XIX. San José: Editorial UCR.

El presidente de Costa Rica anuncia la proclamación de la neutralidad perpetua. (1983, noviembre 18). El País, s.p., Internacional. Recuperado de https://elpais.com/diario/198 3/11/18/internacional/437958022_850215.html

Evans, S. (1999). The Green Republic: A Conservation History of Costa Rica. Austin: University of Texas Press.

Fallas, C. (2015). Costa Rica frente al filibusterismo: la guerra de 1856 y 1857 contra William Walker : defensa y fortalecimiento de las instituciones del Estado. San José: Editorial de la Universidad de Costa Rica.

González, H. y Llancavil, D. (2017). La reconstrucción de un espacio de poder a través de los mapas. El caso de la cartografía misional del Obispado de Villarrica, Chile (1890-1935). Revista de Historia Regional y Local, 9(17), 380-405. doi: http://dx.doi.org/10.15446/historelo.v9n 17.55399

Hobsbawm, E. (1999). Historia del Siglo XX. Buenos Aires: Editorial Crítica. 
Ley de Creación de la Academia Nacional de Policía, $N^{o}$ 9552. (13 de junio, 2018). Recuperado de https://www.imprentanacional.go.cr/pub/2018/06/13/ALCA117_13_06_2018.pdf

Ley de Expropiación de Hacienda Murciélago para Parque Nacional Santa Rosa, $N^{o}$ 6279. (22 de mayo, 1979). Recuperado de http://www.pgrweb.go.cr/scij/Busqueda/Normativa/Normas/nr m_texto_completo.aspx

Marín, C. (1993). Ajuste estructural y condicionalidad cruzada (Estados Unidos y los Organismos Financieros Internacionales). Revista Relaciones Internacionales, 45, 99-114.

Martínez, H. (2017). López Portillo y Carazo Odio: el apoyo al sandinismo 1976-1979. Revista Temas de nuestra América, 33(Número extraordinario), 177-188. doi: https://doi.org/10.15359/ tdna.33-e.9

Molina, I. (2000). La Campaña Nacional (1856-1857). Una visión desde el Siglo XXI. Alajuela: Museo Histórico Cultural Juan Santamaría.

Molina, S. y González, E. (2015). Historia de Costa Rica. San José: EUNED.

Mora, J. \& Pérez, P. (2020). Tipos de bosques en Costa Rica (Mapa). Programa de Estudios Sociales de la Ciencia, la Técnica y el Medio Ambiente. Costa Rica: Centro de Investigaciones Geofísicas de la Universidad de Costa Rica.

Morera, C. y Romero, M. (2013). Aporte de la geografía a la conservación ecológica: trazos de una vieja sinergia. En Morera, C., Romero, M., y Sandoval, L. [Eds.], Geografí, Paisaje y Conservación (pp.15-37). Heredia: Universidad Nacional de Costa Rica e Instituto Panamericano de Geografía e Historia.

Montoya, V. (setiembre, 2011). El espacio y el poder en Latinoamérica y los (des)equilibrios geográficos del poder global. En Barrera, S. (Ed.), Memorias Seminario de Geografía Crítica: Territorialidad, Espacio y Poder en América Latina, 103-109. Recuperado de http://www.bdigital.una 1.edu.co/6173/243/susanabarreralobaton.2011.pdf

Moya, R. (2007, febrero 5). Finca fue expropiada a Anastasio Somoza en 1978. La Nación, s.p., Sucesos. Recuperado de https://www.nacion.com/sucesos/finca-fue-expropiada-a-anastasio-somoza-en-1978/PWTZ2XLDRBFHZGZFZT26UABP5A/story/

Muñoz, M. y Romero, R. (1991). El dilema del Estado costarricense: Seguridad Nacional o Soberanía. En Kruijt, D. y Torres, E. (coord.), América Latina: militares y sociedad-I (pp.147-182). San José: FLACSO.

Palmer, S. (2007). El héroe indicado (o un estado en búsqueda de su nación): Juan Santamaría, La Batalla de Rivas y la simbología liberal, 1880-1895 (pp. 111-131). En Molina, I. (ed.), Industriosa y sobria. Costa Rica en los días de la Campaña Nacional (1856-1857). Vermont: Plumsock Mesoamerican Studies.

Powaski, R. (2000). La Guerra Fría. Estados Unidos y la Unión Soviética, 1917-1991. Barcelona: Editorial Crítica. 
Quirós, L. (2017). Turismo y territorio en áreas naturales protegidas, Parque Nacional Santa Rosa: del monumento nacional a la conservación del bosque tropical seco, Área de Conservación Guanacaste, Costa Rica. Revista Geográfica de América Central, 2(58E), 91-136. doi: https://doi. org/10.15359/rgac.58-2.4

Ramos, R. (2007, febrero 10). Sobre la hacienda El Murciélago La Municipalidad de La Cruz actuó a espaldas de los derechos de Seguridad Pública. La Nación, s.p., Opinión. Recuperado de https://www.nacion.com/opinion/sobre-la-hacienda-el-murcielago/GC K6S2F DIJB4 VJER4IWVFFXOQ4/story/

Reding, A. (1986). Costa Rica Democratic Model in Jeopardy. World Policy Journal, 3(2), 301-315. Recuperado de https://www.researchgate.net/publication/292147857_Costa_Rica_

Rojas, A. (1985). Interés nacional y toma de decisiones: el caso de la neutralidad costarricense. Anuario de Estudios Centroamericanos, 11(1), 79-97.

Rojas, A., Solís, L. (1993). Entre la intervención y el olvido: las relaciones entre Centroamérica y Estados Unidos. Anuario de Estudios Centroamericanos, 19(2), 5-22.

Rowe, C. (2011). Fishing Away Marine Conservation: Poverty, Resource Dependence, and Poor Management in Cuajiniquil, Costa Rica. (Thesis for the degree of Bachelor of Arts with honors, Department of Environmental Studies of Amherst College). Recuperada de https://www.amherst .edu/media/view/337885/original/Clara_Rowe_2011.pdf

Servicio de Parques Nacionales. (1983). Información General Parques Nacionales y Áreas afines (Informe NPOI3238). San José: Ministerio de Agricultura y Ganadería. Recuperado de http:// www.mag.go.cr/bibliotecavirtual/P01-3238.pdf

Stogiannos, A. (2019). The Genesis of Geopolitics and Friedrich Ratzel: Dismissing the Myth of the Ratzelian Geodeterminism. Athens: Springer.

Ugalde, Á. (mayo, 2016). Una breve reseña histórica de mis experiencias en la creación de los Parques Nacionales. En Sáenz, Y. (Ed.), Revista Biocenosis, 30(1-2), 5-14. Recuperado de https:// revistas.uned.ac.cr/index.php/biocenosis/article/view/1421

Vargas, D. (2016). Dinámica del paisaje en áreas afectadas por incendios forestales en el bosque tropical seco del Área de Conservación Guanacaste, Costa Rica. (Tesis para el grado de Licenciatura en Manejo de Recursos Naturales, Universidad Estatal a Distancia). Recuperada de http:// copa.acguanacaste.ac.cr:8080/handle/11606/695 